\title{
Homeostatic Scaling of Vesicular Glutamate and GABA Transporter Expression in Rat Neocortical Circuits
}

\author{
Stéphanie De Gois, ${ }^{1}$ Martin K.-H. Schäfer, ${ }^{2}$ Norah Defamie, ${ }^{1}$ Chu Chen, ${ }^{1}$ Anthony Ricci, ${ }^{1}$ Eberhard Weihe, ${ }^{2}$ \\ Hélène Varoqui, ${ }^{1}$ and Jeffrey D. Erickson ${ }^{1}$ \\ ${ }^{1}$ Neuroscience Center of Excellence, Louisiana State University Health Sciences Center, New Orleans, Louisiana 70112, and ${ }^{2}$ Department of Molecular \\ Neuroscience, Institute of Anatomy and Cell Biology, Philipps University Marburg, 35033 Marburg, Germany
}

\begin{abstract}
Homeostatic control of pyramidal neuron firing rate involves a functional balance of feedforward excitation and feedback inhibition in neocortical circuits. Here, we reveal a dynamic scaling in vesicular excitatory (vesicular glutamate transporters VGLUT1 and VGLUT2) and inhibitory (vesicular inhibitory amino acid transporter VIAAT) transporter mRNA and synaptic protein expression in rat neocortical neuronal cultures, using a well established in vitro protocol to induce homeostatic plasticity. During the second and third week of synaptic differentiation, the predominant vesicular transporters expressed in neocortical neurons, VGLUT1 and VIAAT, are both dramatically upregulated. In mature cultures, VGLUT1 and VIAAT exhibit bidirectional and opposite regulation by prolonged activity changes. Endogenous coregulation during development and homeostatic scaling of the expression of the transporters in functionally differentiated cultures may serve to control vesicular glutamate and GABA filling and adjust functional presynaptic excitatory/inhibitory balance. Unexpectedly, hyperexcitation in differentiated cultures triggers a striking increase in VGLUT2 mRNA and synaptic protein, whereas decreased excitation reduces levels. VGLUT2 mRNA and protein are expressed in subsets of VGLUT1-encoded neocortical neurons that we identify in primary cultures and in neocortex in situ and in vivo. After prolonged hyperexcitation, downregulation of VGLUT1/ synaptophysin intensity ratios at most synapses is observed, whereas a subset of VGLUT1-containing boutons selectively increase the expression of VGLUT2. Bidirectional and opposite regulation of VGLUT1 and VGLUT2 by activity may serve as positive or negative feedback regulators for cortical synaptic transmission. Intracortical VGLUT1/VGLUT2 coexpressing neurons have the capacity to independently modulate the level of expression of either transporter at discrete synapses and therefore may serve as a plastic interface between subcortical thalamic input (VGLUT2) and cortical output (VGLUT1) neurons.
\end{abstract}

Key words: cortex; GABA; presynaptic; glutamate; trafficking; synaptic plasticity; VGLUT1; VGLUT2; VIAAT; synaptic vesicle; homeostatic plasticity; regulation

\section{Introduction}

Activity-dependent changes in excitatory and inhibitory neurons contribute to homeostatic control of pyramidal neuron firing rates in neocortical networks (Turrigiano and Nelson, 2004). Although the number of excitatory and inhibitory synapses increases during the second and third weeks of neuronal differentiation, a constant structural balance of glutamatergic and GABAergic input (4:1) is maintained along pyramidal neuron dendrites (Liu, 2004). Pharmacological manipulation of this excitatory/inhibitory (E/I) balance for $48 \mathrm{~h}$ in differentiated neurons initiates adaptive changes at individual excitatory and inhib-

Received Dec. 21, 2004; revised June 21, 2005; accepted June 22, 2005

This work was supported by National Institutes of Health Grants NS36936 (J.D.E.), 1P29RR16816 (H.V.), and DC03896 (A.R.), and Federal Ministry of Education and Research Grant 01 GS01118 (M.K.-H.S., E.W.). We sincerely thank Drs. Guosong Liu (Massachusetts Institute of Technology, Cambridge, MA) and Jeffrey Magee (Louisiana State University Health Sciences (enter, New Orleans, LA) for their comments, and S. Grewal, L. Marrero, M. Schneider, and H. Hlawaty (Philipps University Marburg, Marburg, Germany) for technical assistance.

Correspondence should be addressed to Hélène Varoqui or Jeffrey D. Erickson, Neuroscience Center, Louisiana State University Health Sciences Center, 2020 Gravier Street, Suite D, New Orleans, LA 70112. E-mail: hvaroq@|suhsc.edu or jerick@|suhsc.edu.

DOI:10.1523/JNEUROSCI.5221-04.2005

Copyright $\odot 2005$ Society for Neuroscience $\quad 0270-6474 / 05 / 257121-13 \$ 15.00 / 0$ itory synapses that act to restore functional E/I balance. Such structural and functional "synaptic scaling" may play predominant roles in developing and synaptically differentiated excitatory and inhibitory neuronal circuits (Davis and Bezprozvanny, 2001; Liu, 2004; Turrigiano and Nelson, 2004; Perez-Otano and Ehlers, 2005). Although significant progress has been made to define postsynaptic contributions to the homeostatic control of E/I synaptic strength, modulation of transmitter storage and release may also play important roles in E/I synaptic plasticity (Murthy et al., 2001; Atwood and Karunanithi, 2002; Burrone et al., 2002; Axmacher et al., 2004).

At central glutamatergic and GABAergic terminals, synaptic vesicles may not be filled to their maximal capacity (Engel et al., 2001; Yamashita et al., 2003), and release from single vesicles is not enough to saturate postsynaptic receptors at some synapses (Liu et al., 1999; Hajos et al., 2000; McAllister and Stevens, 2000; Ishikawa et al., 2002). Therefore, variability in the amount of transmitter loaded into vesicles at central excitatory and inhibitory synapses could significantly contribute to endogenous variations in quantal release measured in cultured neurons (Frerking et al., 1995; Liu et al., 1999) and in synaptic transmission. Recent work showed that the expression of vesicular glutamate 
transporter-1 (VGLUT1) at hippocampal pyramidal neuron synapses during the second and third weeks of postnatal development dramatically increases, resulting in enhanced quantal size (Wojcik et al., 2004; Wilson et al., 2005). Furthermore, decreasing the functional VGLUT1 concentration on cortical synaptic vesicles pharmacologically leads to reduction in the set point for vesicular glutamate filling (Wilson et al., 2005), whereas VGLUT1 transgenic overexpression increases quantal size (Daniels et al., 2004; Wojcik et al., 2004; Wilson et al., 2005). Indeed, the quantum of glutamate released from individual synaptic vesicles by exocytosis is bidirectionally dependent on activity and can be adjusted by endogenous regulation of the synaptic vesicle level of VGLUT1 (Wilson et al., 2005). Thus, altering the number of transporters on vesicles is a critical determinant in establishing quantal size by way of adjusting the level of vesicular filling.

Here, we demonstrate opposite activity-dependent regulation of expression of VGLUT1 and the vesicular inhibitory transporter for GABA (VIAAT/VGAT) in differentiated neocortical neuronal cultures, at the mRNA and synaptic protein levels, supporting a role for presynaptic scaling of vesicular glutamate and GABA storage and release in homeostatic plasticity. In addition, we show that distinct neocortical neurons express both VGLUT1 and VGLUT2, a second isoform associated with many highrelease probability pathways (Fremeau et al., 2001; Varoqui et al., 2002; Liu, 2003). Plasticity of VGLUT1 and VGLUT2 mRNA and protein expression in coexpressing neocortical neurons may provide dual modes of regulation of vesicular glutamate storage and release at individual excitatory synapses.

\section{Materials and Methods}

Cell culture. Primary neocortical neurons were prepared from embryonic day 18 Sprague Dawley rats (Brewer et al., 1993). Briefly, after dissection of the neocortical mantle, the tissue was rinsed twice in $\mathrm{PBS}\left(4^{\circ} \mathrm{C}\right)$ containing $6 \%$ glucose, minced, and then dissociated by trituration with fire-polished Pasteur pipettes in Neurobasal medium supplemented with B27 (Invitrogen, Gaithersburg, MD), $0.5 \mathrm{~mm}$ L-glutamine (BioWhittaker, Walkersville, MD), and $20 \mathrm{~mm}$ HEPES, pH 7.4. Cells were centrifuged for 4 min at $800 \times g$ and resuspended in Neurobasal medium supplemented with B27, 0.5 mM L-glutamine, and $25 \mu \mathrm{M}$ glutamate. Cells were counted in presence of trypan blue and were plated at $7.8 \times 10^{4}$ cells $/ \mathrm{cm}^{2}\left(7.5 \times 10^{5}\right.$ cells per well $)$ in six-well plates precoated with 25 $\mu \mathrm{g} / \mathrm{ml}$ poly-D-lysine (Sigma, St. Louis, MO). Cells were maintained at $37^{\circ} \mathrm{C}$ in a humidified atmosphere containing $5 \% \mathrm{CO}_{2}$ with $50 \%$ medium replacements twice a week with fresh medium without glutamate. Using such procedures, free of the use of serum, $>90 \%$ of the cultured cells represent neurons. When indicated, neocortical neurons were treated on the 19th day in vitro (DIV) with $20 \mu \mathrm{M}$ bicuculline (BIC) (or bicuculline hydrobromide), $1 \mu \mathrm{M}$ tetrodotoxin (TTX), or vehicle (0.1\% DMSO or water) as described previously (Turrigiano et al., 1998).

RNA isolation and reverse transcription. Total RNA was isolated using Qiagen (Valencia, CA) RNeasy MINI kit according to the instructions of the manufacturer. Two wells of a six-well cluster were combined for each $600 \mu \mathrm{l}$ sample, and cell lysis was performed using a $2 \mathrm{~s}$ pulse with a probe sonicator. RNA $(1 \mu \mathrm{g})$ was reverse transcribed using Bio-Rad (Hercules, CA) iScript cDNA synthesis kit (oligo-dT plus random hexamers) according to the instructions of the manufacturer, and the resulting $20 \mu \mathrm{l}$ were sufficient for 10 real-time PCR amplifications. Typical total RNA yields for DIV3 cultures was $4 \mu \mathrm{g} / \mathrm{well}$ and increased to a maximum of 9 $\mu \mathrm{g} /$ well by DIV14. DNase I (1U/ $\mu$ g; Promega, Madison, WI) treatment of the RNA was performed according to the instructions of the manufacturer, and the $\mathrm{C}_{\mathrm{T}}$ results were identical, whether or not DNase I was used. We also determined that a no reverse-transcriptase control reaction yielded no amplification product.

Real-time reverse transcription-PCR. Specific primers for VGLUT1 (Ni et al., 1994; Bellocchio et al., 2000; Takamori et al., 2000), VGLUT2
(Takamori et al., 2001; Fremeau et al., 2001; Herzog et al., 2001; Varoqui et al., 2002), VIAAT/VGAT (McIntire et al., 1997; Sagne et al., 1997), and $\beta$-actin were selected using Beacon Designer Software (Bio-Rad) and synthesized by Invitrogen. Their $5^{\prime}-3^{\prime}$ sequence with nucleotide position were as follows: VGLUT1 (GenBank accession number NM_053859), forward-(1827) ggcagtttccaggacctccactc, reverse-(1979) gcaagaggcagttgagaaggagagag; VGLUT2 (GenBank accession number NM_053427), forward-(3734) gggtatttggtctgtttggtgtcctg, reverse-(3906) cagcacagcaagggttatggtcac; VIAAT (GenBank accession number NM_031782), forward-(368) ctcgggctccaaggaccaggc, reverse-(553) gcggcgaagatgatgaggaacaacc; and $\beta$-actin (GenBank accession number NM_031144), forward(195) taggcaccagggtgtgatggtggg, reverse-(365) cgcagctgattgtagaaggtgtggtg.

The $18 \mathrm{~S}$ primers (TaqMan Ribosomal RNA control reagents) were purchased from PerkinElmer (Wellesley, MA). The 500 bp templates were amplified from cortical cDNA with the following primers: VGLUT1, forward-(1508) acaagacgcgggaggagtggcagt, reverse-(2007) gaaactgctagtgtgcagcttcac; VGLUT2, forward-(3441) gcaatttctactttcatagagtcataga, reverse-(3941) cgcagcaacaaaatgacagttcac; and VIAAT, forward-(267) gacatcctgaaatcggaaggcgag, reverse-(770) gaggttgccgctcaccactacgta. The templates were gel purified, quantitated, and used to further assess the real-time PCR reaction, which was found to be linear over eight orders of magnitude and $>95 \%$ efficient. These templates were also used to determine the copy number at DIV3 for each mRNA species.

The reactions were setup in duplicates in $25 \mu$ l total volume with 5 pmol of each primer, $12.5 \mu \mathrm{l}$ of $2 \times$ SYBRgreen Master Mix (Applied Biosystems, Foster City, CA), and $2 \mu \mathrm{l}$ of template. The PCR cycle was as follows: $95^{\circ} \mathrm{C}$ for $3 \mathrm{~min}, 42$ cycles of $95^{\circ} \mathrm{C}$ for $30 \mathrm{~s}, 60^{\circ} \mathrm{C}$ for $30 \mathrm{~s}$, and $72^{\circ} \mathrm{C}$ for $30 \mathrm{~s}$, and a melt curve analysis was performed at the end of each experiment to verify that a single product per primer pair was amplified. Furthermore, the sizes of the amplified DNA fragments were verified by gel electrophoresis on a 3\% agarose gel. The amplification and analysis were performed using an iCycler iQ Multicolor real-time PCR detection system (Bio-Rad). Samples were compared using the relative $\mathrm{C}_{\mathrm{T}}$ method. The fold increase or decrease was determined relative to a vehicle-treated control after normalizing to a housekeeping gene using $2^{-\Delta \Delta \mathrm{CT}}$, in which $\Delta \mathrm{C}_{\mathrm{T}}$ is (gene of interest $\left.\mathrm{C}_{\mathrm{T}}\right)-\left(\beta\right.$-actin or $\left.18 \mathrm{~S} \mathrm{C}_{\mathrm{T}}\right)$ and $\Delta \Delta \mathrm{C}_{\mathrm{T}}$ is $\left(\Delta \mathrm{C}_{\mathrm{T}}\right.$ treated $)-\left(\Delta \mathrm{C}_{\mathrm{T}}\right.$ control). Similar calculations were used for the developmental expression study, with $\Delta \Delta \mathrm{C}_{\mathrm{T}}$ being $\left(\Delta \mathrm{C}_{\mathrm{T}} \mathrm{DIV} n\right)-\left(\Delta \mathrm{C}_{\mathrm{T}}\right.$ DIV3). To calculate the relative expression of gene $\mathrm{B}$ compared with gene $A$ in a given sample, the fold difference is given by the formula $2^{-\Delta \mathrm{CT}}$ in which $\Delta \mathrm{C}_{\mathrm{T}}$ is $\left(\mathrm{C}_{\mathrm{T}}\right.$ gene $\left.\mathrm{A}\right)-\left(\mathrm{C}_{\mathrm{T}}\right.$ gene $\left.\mathrm{B}\right)$. Two normalizing controls ( $\beta$-actin and $18 \mathrm{~S}$ ) were always included in the real time reverse transcription (RT)-PCR experiments and yielded similar results. Data shown were normalized to the $\beta$-actin housekeeping gene.

Western blot analysis. Cells were rinsed with PBS, harvested on ice by scraping in cold PBS containing $5 \mu \mathrm{g} / \mathrm{ml}$ pepstatin, $5 \mu \mathrm{g} / \mathrm{ml}$ aprotinin, and $5 \mu \mathrm{g} / \mathrm{ml}$ leupeptin, sonicated in the presence of $1 \mathrm{mM}$ PMSF, and centrifuged at $2000 \times g$ for $10 \mathrm{~min}$ at $4^{\circ} \mathrm{C}$. The resulting post-nuclear supernatant (PNS) was divided in two fractions, one of which was further centrifuged at $100,000 \mathrm{rpm}$ for $30 \mathrm{~min}$ at $4^{\circ} \mathrm{C}$ in a TLA100.2 rotor to yield a membrane fraction. The pellet was resuspended in $1 \times$ sample buffer (10\% glycerol, $62.5 \mathrm{~mm}$ Tris, $\mathrm{pH}$ 6.8, $0.02 \%$ bromophenol blue, $2 \%$ SDS, and $50 \mathrm{~mm}$ dithiothreitol) and heated at $65^{\circ} \mathrm{C}$ for $5 \mathrm{~min}$. Protein concentration was determined with a Bradford assay (Bio-Rad), and $2 \mu \mathrm{g}$ of PNS (VGLUT1) and $4 \mu \mathrm{g}$ (VIAAT) or $15 \mu \mathrm{g}$ (VGLUT2) of membrane fraction were size fractionated on $10 \%$ precast Tris- $\mathrm{HCl}$ polyacrylamide gels (Bio-Rad Criterion system) and electrophoretically transferred to a nitrocellulose membrane (Bio-Rad $0.45 \mu \mathrm{m}$ nitrocellulose sandwiches) using standard protocols. VGLUT1, VGLUT2, VIAAT, and synaptophysin were detected using their respective primary antibodies [our guinea pig anti-VGLUT1 or VGLUT2 at 1:4000; guinea pig anti-VIAAT from Chemicon (Temecula, CA) at 1:1000 and mouse anti-p38 from Sigma at 1:5000) and HRP-conjugated anti-guinea pig or mouse IgG secondary antibodies (1:8000; Sigma), followed by enhanced chemiluminescence (West Pico; Pierce Rockford, IL) and exposure to film (Hyperfilm ECL; Amersham Biosciences, Arlington Heights, IL). Fluorescent secondary antibodies and an infrared imaging system (Odyssey; LI-COR, Lincoln, $\mathrm{NE}$ ) was used to detect synaptophysin on the high-protein membrane 
needed to detect VGLUT2 because the ECL signal was saturated (see Fig. 2).

Immunocytochemistry. The culture medium was removed, and the cells were rinsed with PBS and fixed on ice with $-20^{\circ} \mathrm{C}$ methanol for 10 min. Cells were rinsed three times for 10 min with PBS and incubated with blocking buffer $(0.2 \%$ Triton X-100 and $6 \%$ normal goat serum) in PBS at room temperature for $1 \mathrm{~h}$. Primary antibodies diluted in blocking buffer were applied for $3 \mathrm{~h}$ at room temperature. The antisera against VGLUTs were characterized previously (Schäfer et al., 2002; Varoqui et al., 2002): rabbit anti-VGLUT2 (1:1500), guinea pig anti-VGLUT2 (1: 3000), rabbit anti-VGLUT1 (1:1500), and guinea pig anti-VGLUT1 (1: 3000). A rabbit anti-VIAAT antibody (1:1000; Chemicon) and mouse anti-synaptophysin (1:1000, SVP38; Sigma) were also used. After three washes for $10 \mathrm{~min}$ with PBS, species-specific and highly cross-adsorbed secondary antibodies coupled to Alexa 488, 594, or 647 (Molecular Probes, Eugene, OR) diluted 1:200 in blocking buffer were applied for $1 \mathrm{~h}$ at room temperature. All images $(1376 \times 1024$ pixel resolution) were obtained from a Leica (Nussloch, Germany) DMRXA automated upright epifluorescent microscope equipped with a $100 \times$ (numerical aperture of 1.4) oil-immersion lens, a Sensicam QE charge-coupled device digital camera (Cooke Corporation, Romulus, MI), and filter sets suitable for Alexa 488, Alexa 594, and Alexa 647 (Chroma sets 41001, 31004, and 41008/41022; Chroma Technology, Brattleboro, VT). For doublefluorescence quantitation of synaptic signals, Chroma sets 41001 and 31004 or 41008 were used with identical results. For triple labeling, Chroma sets 41001, 31004, and 41022 were used. Images were deconvolved using Slidebook 4.0 software (Intelligent Imaging Innovations, Denver, CO). For puncta quantification, control and BIC images were acquired using equal exposure times in stacks of 15-25 planes at $0.2 \mu \mathrm{m}$ depth intervals and deconvolved with a constrained iterative algorithm, which preserves the original image intensity scale. Analysis involved the creation of a digital binary mask by segmenting areas over threshold from each fluorescence channels within all captured planes and Slidebookdriven mathematical object statistics (size and mean intensity in red and green channels) calculations. Objects were pruned by size $(10<$ voxels $<$ 6000 ), and analysis with a pixel correlation algorithm identified colocalized objects.

Double-labeling in situ hybridization. Frozen rat brain sections from different postnatal ages were cut at $14 \mu \mathrm{m}$ thickness on a Leica cryostat, thaw mounted on adhesive slides, and stored at $-70^{\circ} \mathrm{C}$ until subjected to the prehybridization procedure as described previously (Schäfer et al., 1993, 2002). Detection of two different RNA transcripts in the same tissue section was performed with radioactive- and nonradioactivelabeled probes as published previously with some modifications (Schäfer et al., 2002). Radioactive probes for rat VGLUT2 (nucleotides 22243283; GenBank accession number AF271235) and rat VGLUT1 (nucleotides 387-1394; GenBank accession number U07609) were generated by in vitro transcription using ${ }^{35} \mathrm{~S}$-UTP and ${ }^{35} \mathrm{~S}$-CTP as radioactive label. Digoxigenin (Dig)-labeled probes were generated from the same templates by in vitro transcription with a digoxigenin labeling mix containing $10 \mathrm{~mm}$ each of ATP, CTP, and GTP, $6.5 \mathrm{~mm}$ UTP, and $3.5 \mathrm{~mm}$ dioxigenin11-UTP (Roche Products, Welwyn Garden City, UK). After hydrolysis, probes were purified by sodium acetate precipitation and then added to the hybridization solution $\left(3 \times \mathrm{SSC}, 50 \mathrm{~mm} \mathrm{NaPO}_{4}, 10 \mathrm{~mm}\right.$ dithiothreitol, $1 \times$ Denhardt's solution, $0.25 \mathrm{~g} / \mathrm{l}$ yeast tRNA, $10 \%$ dextran sulfate, and $50 \%$ formamide) to a final concentration of $5 \times 10^{4} \mathrm{dpm} / \mu \mathrm{l}$ or $0.5 \mathrm{ng} / \mu \mathrm{l}$. Fifty microliter hybridization solution was applied to each section, and slides were coverslipped and incubated for $14 \mathrm{~h}$ at $60^{\circ} \mathrm{C}$. Slides were washed in $2 \times$ SSC for $20 \mathrm{~min}$, followed by $30 \mathrm{~min}$ RNase A treatment [ 20 $\mu \mathrm{g}$ RNase A and $1 \mathrm{U} / \mathrm{ml}$ RNase T1 (Roche Products) in $10 \mathrm{~mm}$ Tris, $\mathrm{pH}$ 8.0, $0.5 \mathrm{M} \mathrm{NaCl}$, and $1 \mathrm{~mm}$ EDTA] at $37^{\circ} \mathrm{C}$. The slides were washed at room temperature in decreasing salt concentrations $(1,0.5$, and $0.2 \times$ SSC) for $20 \mathrm{~min}$ each and at $60^{\circ} \mathrm{C}$ in $0.2 \times$ SSC for $1 \mathrm{~h}$, followed by a final rinse at room temperature in $0.2 \times$ SSC and distilled water for $10 \mathrm{~min}$ each. For the detection of nonradioactive hybrids, slides were equilibrated to buffer A ( $100 \mathrm{~mm}$ Tris and $150 \mathrm{~mm} \mathrm{NaCl}, \mathrm{pH}$ 7.5) containing $0.05 \%$ Tween 20 (Merck, Darmstadt, Germany). Blocking was performed by incubation for $1 \mathrm{~h}$ in blocking buffer (buffer A containing 2\% normal lamb serum). Alkaline phosphatase-conjugated anti-Dig Fab fragments (Roche Products) were diluted to $0.25 \mathrm{U} / \mathrm{ml}$ in blocking buffer. After the slides were rinsed with buffer A, the diluted antibody was applied for $24 \mathrm{~h}$ at $4^{\circ} \mathrm{C}$. Excessive antibody was removed by two $10 \mathrm{~min}$ washes in buffer A. Slides were equilibrated to buffer B (100 mM Tris, 100 $\mathrm{mm} \mathrm{NaCl}$, and $50 \mathrm{mM} \mathrm{MgCl}_{2}$, pH 9.4) containing $0.05 \%$ Tween 20 for 10 $\mathrm{min}$. The chromogen solution containing $0.2 \mathrm{~mm} 5$-bromo-4-chloro-3indolyl phosphate and $0.2 \mathrm{~mm}$ nitroblue tetrazolium salt (Roche Products) in buffer B was applied for $6 \mathrm{~h}$ in the dark, and color development was monitored under microscopic control. The reaction was stopped in water, and slides were covered with $\mathrm{K} 5$ photoemulsion (Ilford, Paramus, $\mathrm{NJ}$ ) diluted 1:1 in water for detection of ${ }^{35} \mathrm{~S}$-labeled probes. After exposure for $18 \mathrm{~d}$ in the dark at $8^{\circ} \mathrm{C}$, slides were developed and embedded with gelatin-based medium. Bright- and dark-field microscopic analysis was performed using an Olympus Optical (Tokyo, Japan) AX-70 microscope and the Spot RT slider digital camera (Diagnostic Instruments, Sterling Heights, MI).

Preparation of acute rat cortical slices, cytoplasm collection, and reverse transcription. Sprague Dawley rats (male, 8 week old) were anesthetized with a mixture of ketamine and xylazine and decapitated in accordance with institute animal welfare guidelines. Coronal slices $(300 \mu \mathrm{m})$ through the somatosensory cortex were cut and processed as described previously (Chen et al., 2002). Layer IV was identified based on the depth from the surface and barrel structure (Lübke et al., 2000; Brecht and Sakmann, 2002). Individual neurons were viewed with a Zeiss (Oberkochen, Germany) Axioskop microscope, fitted with a $60 \times$ waterimmersion objective (Olympus Optical) and differential interference contrast (DIC) optics. Whole-cell patch-clamp recordings were made using an Axon 2B amplifier (Axon Instruments). The patch pipettes (2-4 $\mathrm{M} \Omega$ ) were pulled from borosilicate glass with a micropipette puller (Sutter Instruments, Novato, CA) and were filled with $6 \mu$ lof autoclaved internal pipette RT-PCR solution containing the following (mM): 140 $\mathrm{KCl}, 5 \mathrm{HEPES}, 5 \mathrm{EGTA}$, and $3 \mathrm{MgCl}_{2}, \mathrm{pH}$ 7.3. After the establishment of the whole-cell configuration, a depolarizing current was injected to verify that firing was elicited. Then, the cell contents (including the nucleus, in most cases) were aspirated as completely as possible into the patch pipette by application of gentle negative pressure and expelled into a chilled $0.2 \mathrm{ml}$ PCR tube containing $4 \mu \mathrm{l}$ of reverse transcription mixture consisting of the following: $1 \mu \mathrm{l}$ of random hexamers (50 $\mu \mathrm{M}$; Applied Biosystems), $1 \mu \mathrm{l}$ of $100 \mathrm{~mm}$ DTT, $0.5 \mu \mathrm{l}$ of dNTPs (10 mm ea), $0.5 \mu \mathrm{l}$ of Rnasin plus (40 U/ $\mu$ l; Promega), $0.5 \mu$ l of SuperscriptII (200 U/ $\mu$ l; Invitrogen), and $0.5 \mu \mathrm{l}$ of $10 \times$ first-strand buffer. The resulting $10 \mu \mathrm{l} \mathrm{mix}$ was subjected to the following cycle: $5 \mathrm{~min}$ at $25^{\circ} \mathrm{C}, 2 \mathrm{~h}$ at $42^{\circ} \mathrm{C}, 5 \mathrm{~min}$ at $85^{\circ} \mathrm{C}, 4^{\circ} \mathrm{C}$ hold. A positive control consisting of $500 \mathrm{pg}$ of total RNA isolated from control DIV21 primary cortical cultures and diluted into 6 $\mu \mathrm{l}$ of internal solution and a negative control consisting of $6 \mu \mathrm{l}$ of internal pipette solution were processed in parallel.

Single-cell RT-PCR. We used a two-step protocol modified from Cauli et al. (1997) and Dal Bo et al. (2004). The whole first-strand reaction served as a template for a round of multiplex PCR in a final volume of 100 $\mu \mathrm{l}$ and in the presence of all three outside primer sets ( $1 \mu \mathrm{M}$ each), $1 \times$ PCR buffer, $2 \mathrm{~mm} \mathrm{MgCl}_{2}, 200 \mu \mathrm{m}$ each dNTPs, and $2 \mathrm{U}$ of Platinum Taq (Invitrogen). After a $2 \mathrm{~min}$ denaturation at $95^{\circ} \mathrm{C}$, a first step of 20 cycles ( $30 \mathrm{~s}$ at $95^{\circ} \mathrm{C}, 30 \mathrm{~s}$ at $57^{\circ} \mathrm{C}$, and $40 \mathrm{~s}$ at $72^{\circ} \mathrm{C}$ ) was performed. In the second round, each individual transporter cDNA was amplified in $50 \mu \mathrm{l}$ using $2.5 \mu \mathrm{l}$ of the first reaction as a template, $0.5 \mu \mathrm{M}$ specific nested primers set, 35 cycles $\left(30 \mathrm{~s}\right.$ at $95^{\circ} \mathrm{C}, 30 \mathrm{~s}$ at $60^{\circ} \mathrm{C}$, and $40 \mathrm{~s}$ at $72^{\circ} \mathrm{C}$ ). The primer sets for VGLUT1 and VGLUT2 (Dal Bo et al., 2004) and for VIAAT (BeaconDesigner software; Bio-Rad) were designed to flank an intron to eliminate amplification from genomic contaminants. Their $5^{\prime}-3^{\prime}$ sequence with nucleotide position were as follows: VGLUT1, forward-out(132) ccggcaggaggagtttcggaag, reverse-out-(609) agggatcaacatatttagggtggaggtagc, forward-in-(188) tactggagaagcggcaggaagg, reverse-in-(498) ccagaaaaaggagccatgtatgagg; VGLUT2, forward-out-(1235) tgttctggcttctggtctcttacgagag, reverse-out-(1834) ttcccgacagcgtgccaaca, forward-in(1300) aggtacatagaagagagcatcggggaga, reverse-in-(1614) cactgtagttgttgaaagaatttgcttgctc; and VIAAT, forward-out-(318) cccgtcgagggagacattcattatcagc, reverse-out-(621) cctcaccatcttcgttctcctcgtacag, forwardin-(368) ctcgggctccaaggaccaggc, reverse-in-(552) gcggcgaagatgatgaggaacaacc. Single bands of the expected size were resolved on $2.5 \%$ agarose 


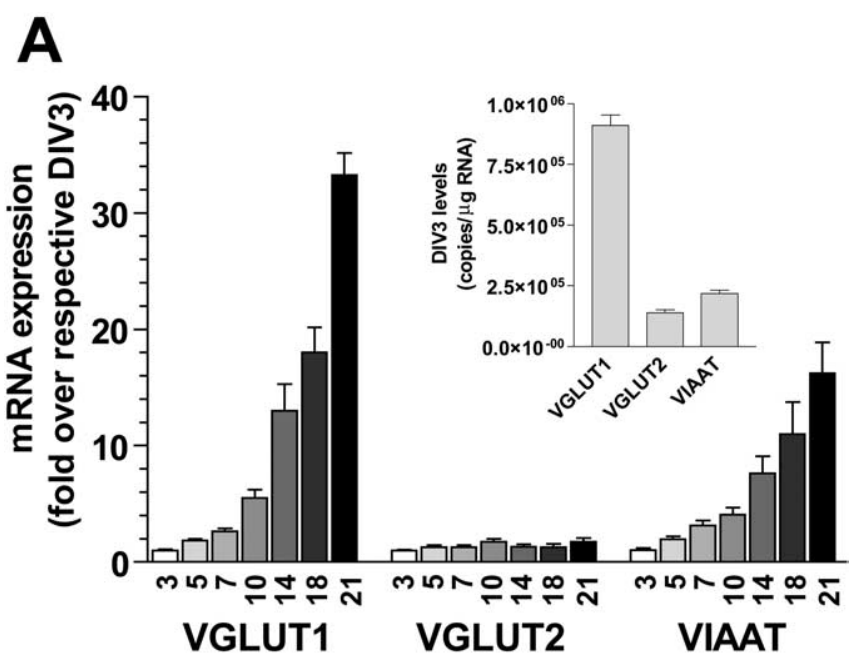

B

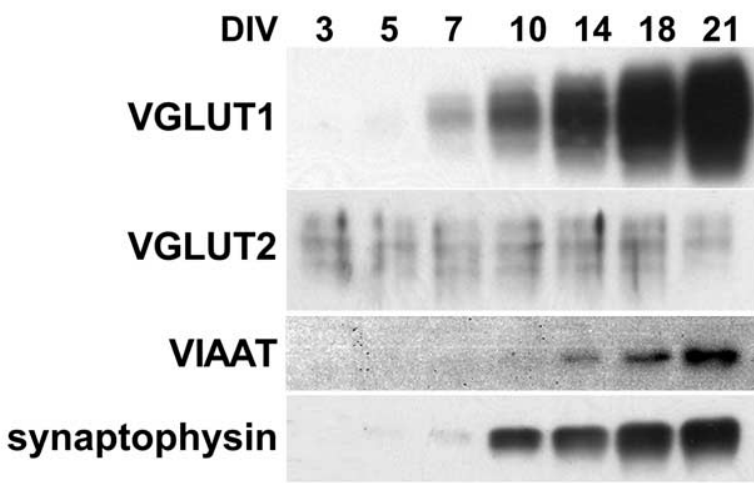

Figure 1. Vesicular excitatory and inhibitory amino acid transporter expression is endogenously regulated during development. $\boldsymbol{A}$, Real-time RT-PCR analysis of VGLUT1, VGLUT2, and VIAAT mRNA in neocortical neurons $\left(7.8 \times 10^{4} / \mathrm{cm}^{2}\right)$ at various times in culture (DIV3-DIV21), normalized for each gene to the level of expression seen at DIV3. VGLUT1 and VIAAT levels increase in parallel during the second and third week in culture, whereas VGLUT2 levels remain fairly constant. Results are presented as means \pm SEM from three independent culture preparations with duplicate wells. Inset, Copy number for each RNA species at DIV3. $\boldsymbol{B}$, Western blot analysis of VGLUT1, VGLUT2, VIAAT, and synaptophysin expression in primary neocortical cultures at various times. VGLUT1 and VIAAT dramatically increase in protein expression during the second and third week in culture, whereas VGLUT2 protein levels remain stable. Synaptophysin expression levels follow a pattern similar to VGLUT1 and VIAAT.

gels after the second step reactions (VGLUT1, $311 \mathrm{bp}$; VGLUT2, $315 \mathrm{bp}$; and VIAAT, $185 \mathrm{bp}$ ), and the identity of the VGLUT1 and VGLUT2 fragments was further confirmed by digestion with HincII enzyme, which yielded two fragments of 207 and $104 \mathrm{bp}$ for VGLUT1 and two fragments of 157 and $158 \mathrm{bp}$ for VGLUT2.

\section{Results}

Coordinated endogenous upregulation of VGLUT1 and VIAAT during neocortical synaptic differentiation in primary culture

The amount of mRNAs encoding VGLUT1 and VIAAT, the predominant vesicular transporters present in excitatory and inhibitory synapses, is relatively low during the first week, but a striking increase in expression ( $>10$ fold) of both occurs between DIV7 and DIV21 (Fig. 1A). During this time, a relatively constant VGLUT1/VIAAT mRNA ratio of 6:1 (three independent cultures) is observed. VGLUT2 mRNA levels in culture are rather stable throughout development and considerably lower than VGLUT1 (for absolute copy number at DIV3, see Fig. 1, inset). The developmental regulation of VGLUT1 and VGLUT2 protein
(Fig. $1 B$ ) follows a trend similar to the mRNA. VIAAT protein expression, like VGLUT1, also increases during the second and third week in vitro together with synaptophysin, a general marker for synaptic vesicles (Fig. $1 \mathrm{~B}$ ). The marked increase in VGLUT1 and VIAAT expression during this time is comparable with the postnatal developmental expression of these gene products in vivo (Minelli et al., 2003a,b). The lower VGLUT2 levels observed may reflect a lower abundance of subclasses of VGLUT2expressing excitatory neurons compared with VGLUT1-encoded pyramidal neurons [see in situ hybridization histochemistry (ISHH) results]. Together, our results indicate that VGLUT1 and VIAAT expression are endogenously coregulated during postnatal development in a manner that may serve to balance excitatory and inhibitory transmission through periods of increased synaptogenesis, synaptic release of glutamate and GABA, and functional neocortical connectivity.

\section{Bidirectional and opposite activity-dependent changes in VGLUT1, VGLUT2, and VIAAT expression in mature neocortical neurons}

To assess whether VGLUT1, VGLUT2, and VIAAT mRNA and total protein expression in dissociated primary cultures of rat neocortex is affected by a prolonged perturbation of activity, we treated fully differentiated cultures (DIV19) with BIC (20 $\mu \mathrm{M})$ or $\operatorname{TTX}(1 \mu \mathrm{M})$ for $48 \mathrm{~h}$. We equate treatment with these pharmacological agents as increased or decreased activity, respectively, based on extensive electrophysiological analysis in similar preparations of primary cortical neurons (Turrigiano and Nelson, 2004; Perez-Otano and Ehlers, 2005 and references therein). BIC, a $\mathrm{GABA}_{\mathrm{A}}$ receptor antagonist, causes endogenous hyperexcitation that increases pyramidal neuron firing rate (by decreasing feedback inhibition). Intrinsic adaptive mechanisms engage during the next $48 \mathrm{~h}$ that adjust the quantal amplitude of excitatory and inhibitory responses (miniature EPSCs) measured postsynaptically. Hence, spontaneous pyramidal neuron firing is stabilized and firing rates return to control levels (Turrigiano et al., 1998). After BIC treatment, VGLUT1 mRNA levels decrease by $\sim 34 \%$ (Fig. 2A). In contrast, TTX treatment, which blocks all depolarization mediated by $\mathrm{Na}^{+}$channels, leads to a $41 \%$ increase in VGLUT1 mRNA levels (Fig. 2A). Conversely, TTX treatment leads to a decrease in the level of VIAAT mRNA $(58 \%)$ (Fig. 2A), whereas BIC treatment leads to an increase in VIAAT mRNA levels (29\%) (Fig. 2A). These results demonstrate bidirectional and opposite regulation of VGLUT1 and VIAAT mRNA levels by prolonged activity changes. Qualitatively similar changes in total VGLUT1 and VIAAT protein levels are also observed by Western blot (Fig. $2 B$ ). Unexpectedly, we find that VGLUT2 mRNA expression increases dramatically (15-fold) after BIC treatment (Fig. 2A). VGLUT2 protein detected in membrane fractions by Western blot is also markedly increased after a $48 \mathrm{~h}$ BIC treatment (Fig. 2 B). Although VGLUT2 mRNA levels are low in differentiated control cultures compared with VGLUT1, an additional reduction is induced by TTX treatment (47\%) (Fig. 2A). These results demonstrate bidirectional and opposite regulation of VGLUT1 and VGLUT2 mRNA levels by prolonged activity changes. Two days of treatment with BIC or TTX does not affect the level of expression of synaptophysin (Fig. $2 B)$. Two days of treatment with BIC and TTX combined results in vesicular transporter changes similar to those observed under TTX alone (Fig. 2A). Gabazine $(20 \mu \mathrm{M})$, a highly specific $\mathrm{GABA}_{\mathrm{A}}$ receptor antagonist (Heaulme et al., 1986), produced a similar VGLUT2 mRNA induction as BIC (data not shown). 

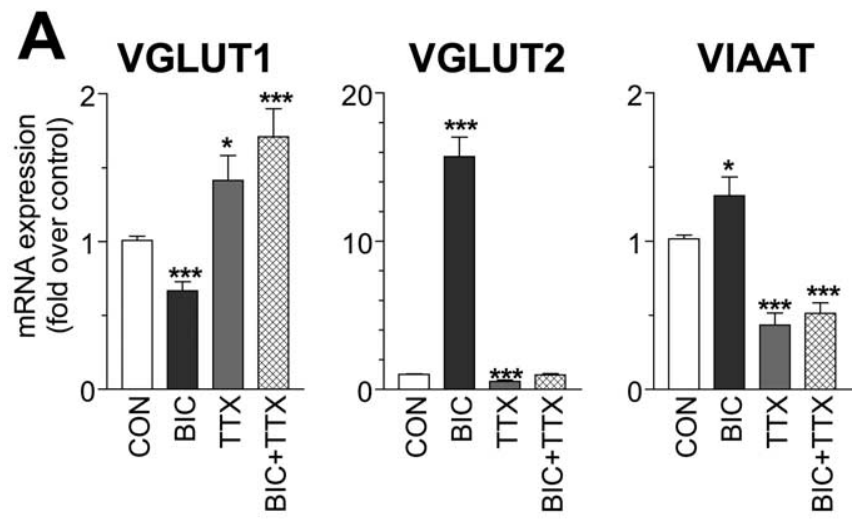

B

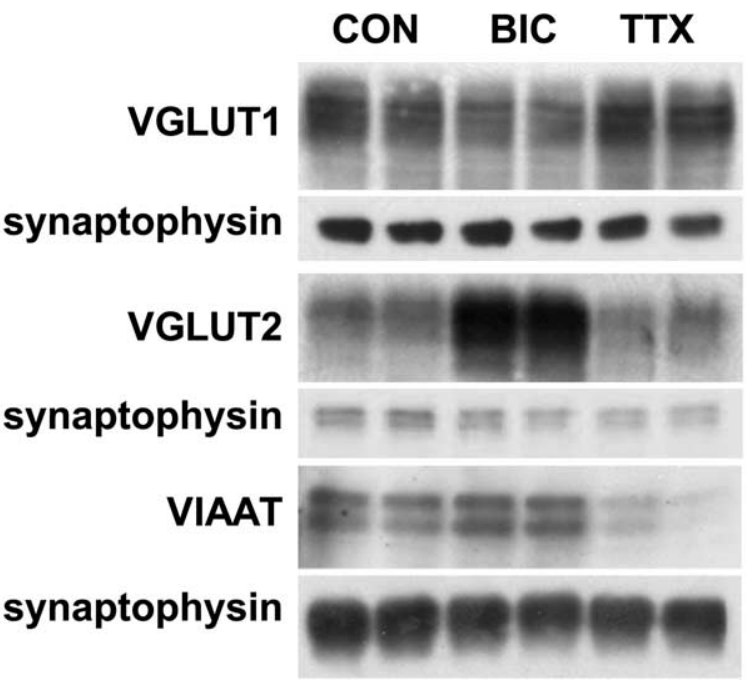

Figure 2. Bidirectional activity-dependent regulation of VGLUT1, VGLUT2, and VIAAT mRNA and protein expression in differentiated neocortical networks. $A$, Real-time RT-PCR analysis of the mRNA expression of the three vesicular transporters (fold over vehicle-treated controls) is examined in differentiated (DIV21) neurons $\left(7.8 \times 10^{4} / \mathrm{cm}^{2}\right)$ and reveals bidirectional changes in expression for VGLUT1, VGLUT2, and VIAAT after $48 \mathrm{~h}$ treatment with $20 \mu \mathrm{m}$ BIC or $1 \mu \mathrm{m} \mathrm{TTX.}$ Results are presented as means \pm SEM from at least eight independent culture preparations with duplicate wells. Note in the BIC plus TTX condition (3 independent cultures) that neurons behave like in the TTX-only condition. Also note that VGLUT2 and VIAAT changes are opposite to those observed for VGLUT1. Significance of the findings was assessed by two-tailed Student's unpaired $t$ test against control values. ${ }^{*} p<0.01 ;{ }^{* *} p<0.001 ;{ }^{* * *} p<0.0001$. B , Western blot analysis of VGLUT1, VGLUT2, and VIAAT with synaptophysin controls. Note the modest changes in VGLUT1 and VIAAT protein with BIC and TTX treatment relative to synaptophysin and the robust increase in VGLUT2-immunoreactive band after BIC treatment. CON, Control.

\section{Colocalization of VGLUT2 in subsets of VGLUT1-containing} neocortical axonal processes and synapses

A central question in the field is why there are multiple isoforms of the vesicular glutamate transporter. Neocortical neuronal cultures allow us to study VGLUT1-encoded pyramidal neurons and intrinsic VGLUT2-expressing excitatory neurons. Here, we examined the extent of colocalization of VGLUT1 and VGLUT2 in developing and differentiated neurons. Cell body labeling is not observed by immunocytochemistry in differentiated neocortical neurons using antibodies directed against VGLUT1, VGLUT2, VIAAT, and synaptophysin (Figs. 3, 4). However, axonal processes can be identified during the first postnatal week of development as VGLUT1 and VGLUT2 containing puncta are trafficked to their respective terminals and appear as regular and irregular-shaped "beads on a string" (Fig. $3 A$ ). In some neuronal processes $(>10 \%)$, VGLUT1- and VGLUT2-containing immu- noreactive puncta colocalize (yellow) throughout the length of the axonal projections (DIV5-DIV9) (Fig. 3A). Similar degrees of coexpression are observed in hippocampal dissociated cultures (Wojcik et al., 2004) (but see autapses of Fremeau et al., 2004b).

VGLUT1 mRNA and protein is expressed in most pyramidal neurons in situ (Ni et al., 1995; Bellocchio et al., 1998), and VGLUT1-encoded excitatory synapses predominate in adult neocortex (Fremeau et al., 2004a) as they do in differentiated neocortical cultures (DIV21). VGLUT2-expressing puncta are evenly distributed in differentiated cultures, like VGLUT1, but are reduced in number $(\sim 25 \%)$. On occasion, strongly labeled VGLUT2 puncta are observed along beaded varicosities that can be traced back to a strongly labeled cell soma in developing and differentiated cultures (data not shown). These VGLUT2 neurons are unusual in displaying cell body labeling and are present at low abundance in our preparation $\left(\sim 44 \pm 10\right.$ per $7.5 \times 10^{5}$ cells originally plated; eight independent cultures) as they are in hippocampal cultures (Wojcik et al., 2004).

In differentiated cultures, double-labeling experiments indicate that most of the VGLUT-immunoreactive puncta contain only one isoform, whereas $<10 \%$ of the VGLUT1 puncta contain both transporters (Fig. 3B). A similar fraction of cortical excitatory synapses (hippocampus) contain both VGLUT1 and VGLUT2 in vivo (Boulland et al., 2004). Nearly all VGLUT1 synapses contain synaptophysin (>90\%), whereas VGLUT2/synaptophysin copositive synapses comprise only $30-35 \%$ of the total VGLUT2-containing puncta observed. Triple-labeling experiments conclude that most VGLUT2/synaptophysin copositive terminals also contain VGLUT1 (Fig. 3C). Like most VGLUT1only expressing synapses, VGLUT2/VGLUT1 copositive puncta are juxtaposed to postsynaptic density-95 (PSD95)-containing postsynaptic specializations (Fig. 3D) that are associated with glutamate receptor trafficking and excitatory transmission (Cline, 2005). The nature of the many VGLUT2-positive puncta observed that do not colocalize with synaptophysin (and VGLUT1) and are distributed at sites that do not face PSD95containing postsynaptic specializations (Fig. $3 D$ ) is unknown at present. The immunolabeling of some of these structures appear somewhat less uniform in shape than are the puncta at VGLUT1/ VGLUT2 coexpressing synapses (Fig. 3C,D). They may represent trafficking intermediates, like those seen in developing neurons (Fig. 3A), or novel sites of glutamate storage and release.

\section{Synaptic scaling of VGLUT1, VGLUT2, and VIAAT expression by activity}

We examined the synaptic expression of the vesicular glutamate and GABA transporters after a persistent period of hyperexcitation (BIC treatment, $48 \mathrm{~h}$ ) by double-immunofluorescence deconvolution microscopy. We assessed changes in the ratios of fluorescence intensity of transporter protein to synaptophysin at single synapses. Like VGLUT1 (>90\%), a majority $(>60 \%)$ of VIAAT-containing puncta observed in differentiated cultures contain synaptophysin. We find opposite changes in the ratios of intensity of VGLUT1/ synaptophysin and VIAAT/synaptophysin fluorescent puncta (Fig. $4 A, D$ ). Thus, at individual excitatory and inhibitory synapses (two independent cultures), VGLUT1/synaptophysin ratios are decreased (15\%) (Fig. 4C), whereas VIAAT/synaptophysin ratios are increased (25\%) (Fig. 4F). The cumulative plots illustrate this phenomenon: the intensity of VGLUT1 puncta shifts to the left and VIAAT shifts to the right, whereas the synaptophysin intensity in the corresponding puncta remains unchanged (Fig. 4B,E). These results parallel the opposite changes in VGLUT1 and VIAAT mRNA and total protein levels observed under BIC treatment (Fig. 2). VGLUT1 
synaptic results are similar to those reported recently in differentiated hippocampal neuronal cultures after BIC treatment $(48 \mathrm{~h})$ in which somewhat greater $(30 \%)$ reductions in VGLUT1/synapsin or VGLUT1/synaptotagmin intensity ratios at excitatory synapses are observed with a corresponding reduction in the amount of glutamate released at synapses from single vesicles (Wilson et al., 2005). A similar role for VIAAT in filling synaptic vesicles with GABA can be expected.

The immunofluorescence intensity of all VGLUT2-positive puncta is markedly increased after $48 \mathrm{~h}$ treatment with BIC (Figs. $3 B, 4 G$ ). The total number of VGLUT2-positive synaptic puncta (four independent cultures, 25 images) between similarly sized fields of control $(25,965$ puncta) and BIC treated (25,686 puncta) neurons remains unchanged. Instead, the intensity of VGLUT2 immunofluorescence increases (Fig. 3B), with average intensity increase of $1.46 \pm 0.08$. When the VGLUT2 mean intensity at a synapse is normalized to synaptophysin levels (30$35 \%$ of VGLUT2 puncta), a similarly increased VGLUT2/synaptophysin fluorescence ratio of $1.57 \pm 0.04$ is observed for BIC-treated cultures (representative experiment of $n=950$ and 956 boutons for control and BIC) (Fig. 4I). The level of synaptophysin in boutons that contain VGLUT2 does not change significantly with BIC treatment (Fig. 4G,H). These data suggest that the upregulation of VGLUT2 mRNA observed after BIC treatment of differentiated neocortical neurons results in increased levels of total VGLUT2 protein and increased levels of VGLUT2 in synaptophysin-positive synaptic terminals and at synaptophysin-negative sites. At VGLUT1/VGLUT2 coexpressing synapses, VGLUT2/VGLUT1 ratios show an increase of $1.70 \pm 0.16$ after BIC treatment ( $n=9,10,479$ boutons analyzed for control vs 9025 boutons for BIC), somewhat greater than the increased ratios observed for VGLUT2/synaptophysin (Fig. 4I) or VGLUT2 alone. Together, our results suggest that VGLUT1-encoded neocortical excitatory neurons downregulate this transporter and vesicular glutamate filling at all (or many) of their synapses after BIC treatment (Figs. $3 B, 4 A, C$ ), whereas a subset of VGLUT1 synapses increase expression of VGLUT2 (Fig. 3B). Because no differences in intrinsic transport properties of VGLUT1 and VGLUT2 or between endogenous VGLUT1- or VGLUT2-filled vesicles have been reported, it is likely that the number of VGLUT2 molecules, like VGLUT1, is a critical determinant for vesicle glutamate filling. Within these coex-
A
VGLUT1
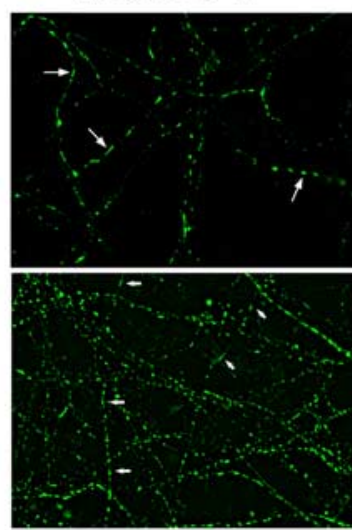

B
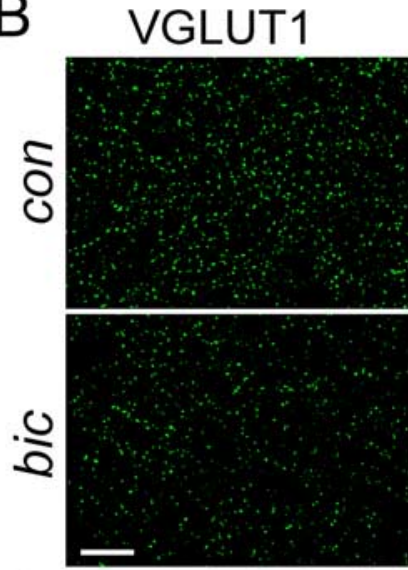

C

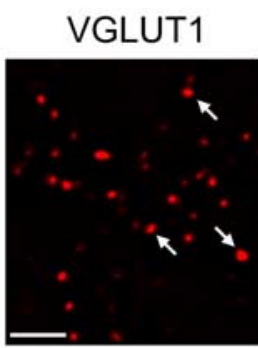

D

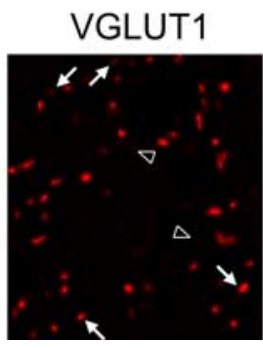

VGLUT2

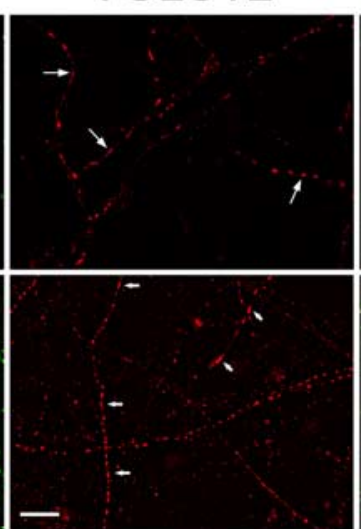

VGLUT2
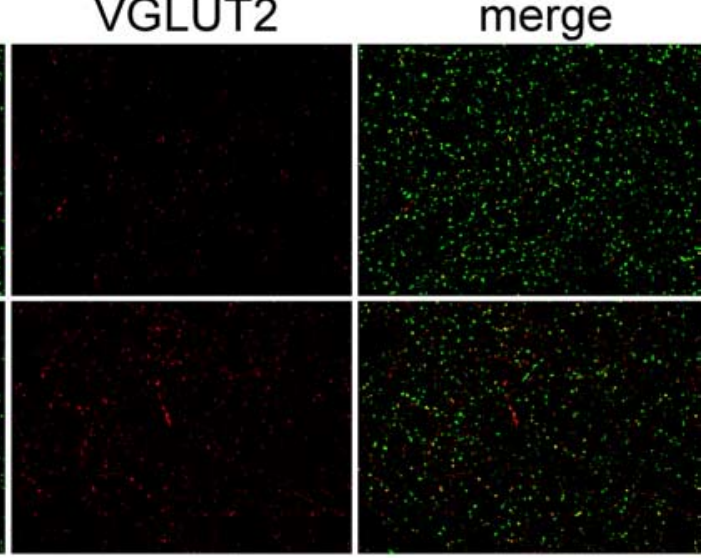

synaptophysin

merge
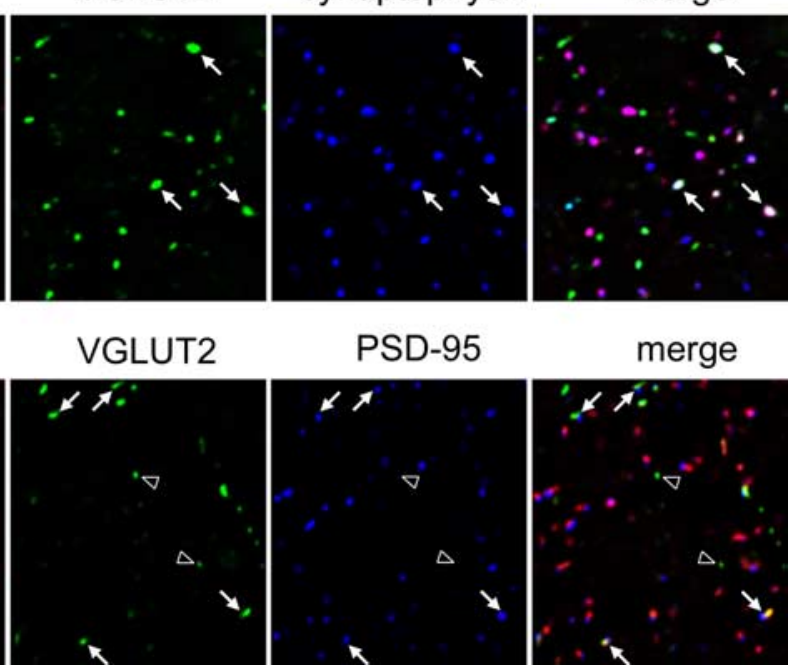

PSD-95
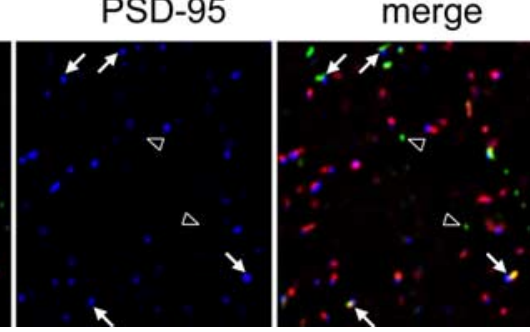

Figure 3. VGLUT1 and VGLUT2 coexpression in neocortical axonal processes during development and at discrete synapses in differentiated cultures. A, Endogenous expression of VGLUT1 (green), VGLUT2 (red), and merged images in neocortical cultures at DIV7. Single Z planes of deconvolved (nearestneighbor) images are shown. Note the coexpression of VGLUT1 and VGLUT2 on some axonal processes that appear as beads on a string. Scale bar, $10 \mu \mathrm{m}$. B, VGLUT1 (green) and VGLUT2 (red) immunoreactivity appears as discrete puncta in differentiated neocortical cultures (DIV21) in control condition (top row; con) and after $48 \mathrm{~h} \mathrm{BIC-treatment} \mathrm{(bottom} \mathrm{row).} \mathrm{Equal}$ acquisition times reveal an apparent increase in intensity of VGLUT2-labeled puncta (middle) and decrease in intensity of VGLUT1-labeled puncta (left). Individual Z planes from deconvolved images are shown. Note the colocalization (yellow) of VGLUT1 and VGLUT2 at some differentiated synaptic sites in control and BIC-treated neurons (right). Scale bar, $10 \mu \mathrm{m}$. C, Triple labeling with VGLUT1 (red), VGLUT2 (green), and synaptophysin (blue) reveals a distinct set of synapses that coexpress both transporters. Note arrow showing VGLUT1 and VGLUT2 colocalized at synapses that appear white. Also note that most VGLUT1 puncta are colocalized with synaptophysin (pink, merged panel), whereas many VGLUT2 puncta are not. D, Triple labeling with VGLUT1 (red), VGLUT2 (green), and PSD95 (blue) shows that the majority of VGLUT1-only and VGLUT1/NGLUT2 coexpressing synapses (yellow, arrow) are juxtaposed to postsynaptic PSD95-containing puncta, whereas other VGLUT2-only puncta (arrowhead) are not. Scale bar, $5 \mu \mathrm{m}$. 
A
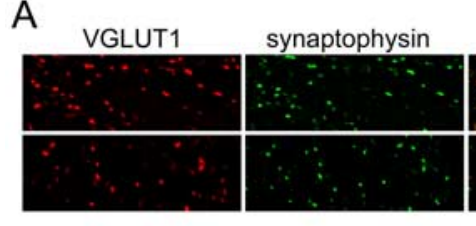

D
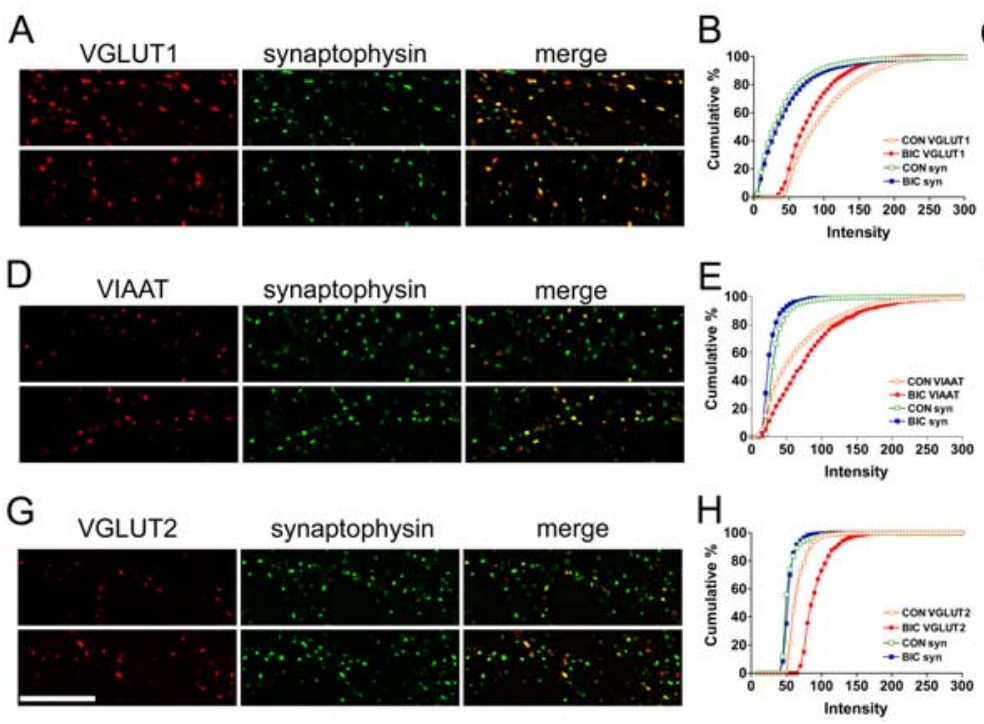

Figure 4. Activity-dependent scaling of VGLUT1, VIAAT, and VGLUT2 expression in differentiated neocortical synapses. Deconvolved images of control (top rows) and BIC-treated (bottom rows) cultures acquired with equal exposure time showing VGLUT1/ synaptophysin (A), VIAAT/synaptophysin (D), and VGLUT2/synaptophysin ( $\boldsymbol{G}$ ) colabeling. Analysis of fluorescence intensity was restricted to neuronal puncta that contain the synaptic vesicle marker synaptophysin. Scale bar, $10 \mu \mathrm{m}$. The intensity profile for VGLUT1 $(\boldsymbol{B})$ is left shifted, whereas VIAAT $(\boldsymbol{E})$ and VGLUT2 $(\boldsymbol{H})$ profiles are right shifted in BIC-treated cultures on the cumulative percentage plot, whereas synaptophysin remains stable. Quantitation of mean transporter/synaptophysin intensity ratios in individual coexpressing puncta reveals a decrease in VGLUT1 ( $(\boldsymbol{C})$ and increases in VIAAT $(\boldsymbol{F})$ and VGLUT2 $(\boldsymbol{I})$. Results shown are representative experiments that include $>1000$ synapses. ${ }^{* * *} p<0.001$. CON, Control.

pressing synapses, it is presently unknown whether VGLUT1 and VGLUT2 are located on the same vesicles or on two populations of synaptic vesicles. Either way, increased expression of VGLUT2 in a subset of VGLUT1 terminals may prevent a reduction in vesicular glutamate filling and release that would be expected at VGLUT1-containing excitatory synapse after BIC treatment (Wilson et al., 2005).

\section{Coexpression and endogenous regulation of VGLUT1 and VGLUT2 mRNA in neocortical pyramidal neurons in situ} Our results in cultured neocortical neurons suggest that VGLUT1 and VGLUT2 are coexpressed in some cells and that VGLUT1 and VGLUT2 expression is bidirectionally regulated by activity. To determine whether VGLUT1 and VGLUT2 are coexpressed in individual neocortical neurons in vivo, we first examined the developmental expression pattern by double-labeled ISHH. Radiolabeled ISHH studies led us to estimate that VGLUT1 mRNA levels are at least 100 times greater than VGLUT2 in the adult rat cerebral cortex and considerably higher than VGLUT2 throughout development (supplemental figure, available at www.jneurosci.org as supplemental material). Therefore, to determine whether some neocortical neurons coexpress VGLUT1 and VGLUT2, we performed double-labeling ISHH with ${ }^{35}$ S-labeled VGLUT2 and digoxigenin-labeled VGLUT1, because chromogenic detection methods are less sensitive. The lack of hybridization signal using the corresponding sense probes indicates the specificity of the hybridization experiments (data not shown).

VGLUT2 mRNA is more abundantly expressed in superficial cortical layers (I/II) during the first postnatal week than at later developmental stages $(p>10)$ (Fig. 5) (supplemental figure, available at www.jneurosci.org as supplemental material). During the first 2 weeks [up to postnatal day 10 (P10)], VGLUT2 mRNA expression increases in upper neocortical layers (II/III)
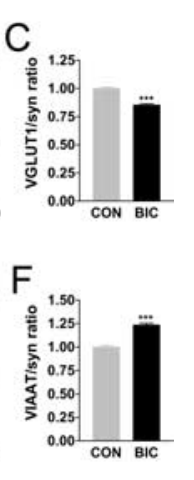

and particularly in small neurons in layer IV. Strongly labeled, VGLUT2-positive neurons also appear during this time in deeper cortical layers (V/VI) as shown in auditory and parietal cortex (Fig. 5). In adult neocortex, VGLUT2 levels are most evident in layer IV neurons and have disappeared from layer I and decreased dramatically in the superficial layers (II, III) (Fig. 5). However, in deeper cortical regions (e.g., auditory cortex), VGLUT2 levels also remain elevated in some cells in adult (Figs. 5, 6H). Cells expressing VGLUT2 mRNA are most evident in the parietal cortex (Fig. 5), the temporal/auditory cortex (Fig. 6G,H), and the posterior cingulate cortex (retrosplenial cortex) (Fig. 6I,J) (supplemental figure, available at www.jneurosci.org as supplemental material) throughout development. Similar regional differences in VGLUT2 mRNA expression in neocortical layers have been reported in the adult rat (Hisano et al., 2000).

The ISHH analysis of VGLUT1 mRNA expression with ${ }^{35} \mathrm{~S}$ - and digoxigeninlabeled probes shows an increase in cortical layers II-VI between P4 and P14, and a stable expression from P14 on to adulthood (Fig. 5) (supplemental figure, available at www.jneurosci.org as supplemental material). We reported previously a similar temporal pattern of expression by Northern blot (Schäfer et al., 2002). VGLUT1 protein is also strikingly upregulated in pyramidal neuronal layers in rat cerebral cortex between postnatal days 7 and 14, although layer IV neurons have lower content of VGLUT1 mRNA and protein in adult (see Fig. 8) (Minelli et al., 2003b).

High-power images of VGLUT1 and VGLUT2 colabeled neurons from various layers and regions during development and in adult are shown in Figure 6. We find that many neurons in layers II-IV in parietal and auditory cortices coexpress VGLUT1 and VGLUT2 at P10 (Fig. 6A,C) (supplemental figure, $G$ and $H$, available at www.jneurosci.org as supplemental material). Many colabeled cells are also found in layer V/VI in auditory cortex (Fig. 6G) and in the retrosplenial cortex (Fig. 6I). In adult, the level of VGLUT2 is significantly decreased in most pyramidal neurons and is somewhat less in layer IV compared with P10. In layer IV neurons, VGLUT2/VGLUT1 coexpression is found in an abundant population of small round/oval cells (Fig. $6 F$ ) compared with most larger pyramidal neurons in layers III and V (Fig. $7 A$ ). In the parietal and auditory cortices, VGLUT2 levels remain above background in some neurons in layers II/III (Fig. 6B,D) and are quite high in a subpopulation of VGLUT1-positive neurons in layer V/VI (Fig. $6 H$ ). Numerous VGLUT1/VGLUT2 coexpressing neurons with elevated VGLUT2 mRNA levels are also found in the retrosplenial cortex in adult (Fig. $6 \mathrm{~J}$ ).

Pyramidal neurons expressing only VGLUT1 mRNA are found in all cortical layers. Most VGLUT2-positive neurons contain VGLUT1, but scattered VGLUT2-positive, VGLUT1negative neurons are present in layer V/VI, particularly in the auditory cortex (data not shown). Our double-ISHH identification of multiple classes of excitatory neurons in neocortex in situ is in agreement with the types of excitatory neurons (and their 

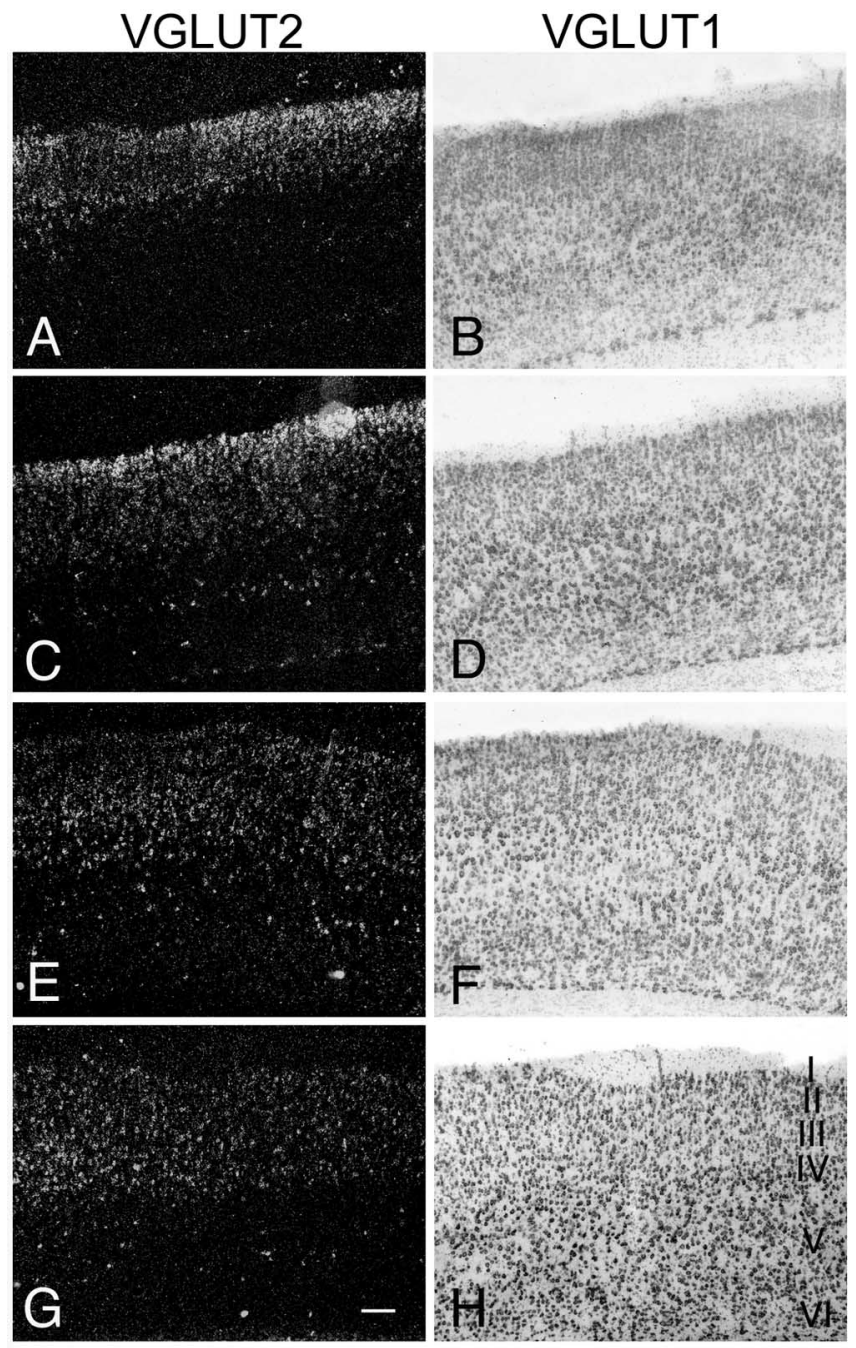

Figure 5. Developmental regulation of VGLUT1 and VGLUT2 mRNA expression in rat neocortex in situ. Left, Dark-field photographs of emulsion-coated autoradiograms showing of VGLUT2 RNA transcripts at various developmental ages (top, P7, P10, P14; bottom, adult) in parietal cortex. Note the relatively robust VGLUT2 labeling in layer I-III in early development $(\boldsymbol{A})$ is further increased during the first 2 postnatal weeks $(\boldsymbol{C})$ but then starts to diminish until adulthood $(\mathbf{G})$. Also note the increase in VGLUT2 labeling in layer IV and in scattered neurons in layer V/VI (E) during second postnatal week, which remains at a moderate expression level in adulthood $(\boldsymbol{F})$. Right, Bright-field photographs of the same sections revealing VGLUT1 staining using a digoxigenin-labeled probe. Note the increase in VGLUT1 expression in all cortical layers in second postnatal week $(\boldsymbol{B}, \boldsymbol{D}, \boldsymbol{F})$ and the high expression levels in adult $(\mathrm{H})$, particularly in layers $V$ and VI. Exposure time for VGLUT2, 38 h. Scale bar, $200 \mu \mathrm{m}$.

abundance) in neocortical cultures that express VGLUT1, VGLUT2, and both VGLUT1 and VGLUT2 by immunofluorescence studies in early development (DIV5-DIV7) (Fig. 3A). In mature neurons, pyramidal neurons expressing only VGLUT1 are the predominant excitatory cell type present in cerebral cortex and in neocortical cultures. VGLUT1/VGLUT2 coexpressing pyramidal and nonpyramidal neurons make up a smaller, but significant, population of cells, whereas neurons expressing only VGLUT2 are a minority. VGLUT2 levels decrease in most neocortical neurons between P10 and P21, during which time VGLUT1 levels increase. This intracortical VGLUT1/VGLUT2 system differs from that seen in cerebellar granule neurons, in which a complete switch of expression of VGLUT2 to VGLUT1 is reported (Miyazaki et al., 2003), and instead may represent endogenous coexpression and differential regulation of VGLUT2 and VGLUT1 mRNA expression in distinct populations of neocortical neurons. Collectively, our new findings indicate that individual neocortical pyramidal neurons in layers II/III and V/VI and, in particular, many small excitatory neurons in layer IV express the mRNA for both isoforms and have the capacity to independently regulate the expression of VGLUT1 and VGLUT2 during neuronal maturation and may retain this potential after they reach maturity.

\section{VGLUT1 and VGLUT2 coexpression in layer IV neurons in} adult rat cortex in vivo

Our double-labeled ISHH study shows that most VGLUT2expressing cells in neocortex also express VGLUT1, including many small neurons in layer IV (Fig. $7 \mathrm{~A}, C$ ). To further confirm that VGLUT1 and VGLUT2 mRNA coexpression occurs in adult rat neocortex, we performed single-cell RT-PCR on layer IV neurons (Fig. 8). Clusters of layer IV neurons were found $\sim 700-800$ $\mu \mathrm{m}$ below the cortex slice surface as described previously (Lübke et al., 2000). Neurons of healthy appearance under DIC observation (flat, smooth surface, nondelineated nucleus) were selected, and their ability to fire after current injection was verified. Spiny layer IV neurons, i.e., spiny stellate and star pyramidal cells (Cowan and Stricker, 2004; Staiger et al., 2004), are easily distinguished by their spherical-to-ovoid somata and the absence of a prominent apical dendrite. Pyramidal neurons, with a thick apical dendritic shaft, are apparent in regions containing many fiber tracts. We harvested the cytoplasm of large pyramidal-shaped cells and smaller cells with spherical-to-ovoid somata. In samples in which a PCR product could be amplified, three excitatory neuronal cell types were identified. Large pyramidal-shaped neurons contained only VGLUT1 (five of five) (Fig. $8 B, C$ ). Cells with an oval/ rounded somata contained both VGLUT1 and VGLUT2 (6 of 15), VGLUT1 only ( 5 of 15), or VIAAT only ( 4 of 15) (Fig. 8 B, C). We did not detect VGLUT2-only neurons by single-cell RT-PCR (30 total cell nuclear cytoplasms extracted). Ten reactions gave no PCR product, which could be attributable to transporter-negative cells, incomplete cytoplasm harvest, or RNase contamination. VGLUT1/ VGLUT2 coexpressing excitatory layer IV neurons, together with VGLUT1/VGLUT2 coexpressing layer II/III and V/VI pyramidal neurons, likely are responsible for the activity-dependent changes in VGLUT2 expression observed in differentiated neocortical neuronal culture.

\section{Discussion}

The major findings of the present study are that (1) VGLUT1 and VIAAT exhibit bidirectional and opposite regulation at the molecular level after persistent activity changes in mature neocortical neuronal cultures, and (2) VGLUT1 and VGLUT2 also display bidirectional and opposite modes of regulation by activity and are coexpressed in subsets of neocortical pyramidal neurons (layers II/III and V/VI) and in many small neurons in layer IV in adult rats in vivo, in subsets of axonal processes in developing cultures, and at a distinct set of VGLUT1- and synaptophysin-containing synapses that face PSD95-containing postsynaptic densities in differentiated neurons. Our data support an important role for regulated vesicular transporter expression and consequent scaling of synaptic vesicle transmitter storage, and release, at both excitatory and inhibitory synaptic terminals during synaptic differentiation and in the homeostatic response of neocortical networks to activity in mature neurons. 

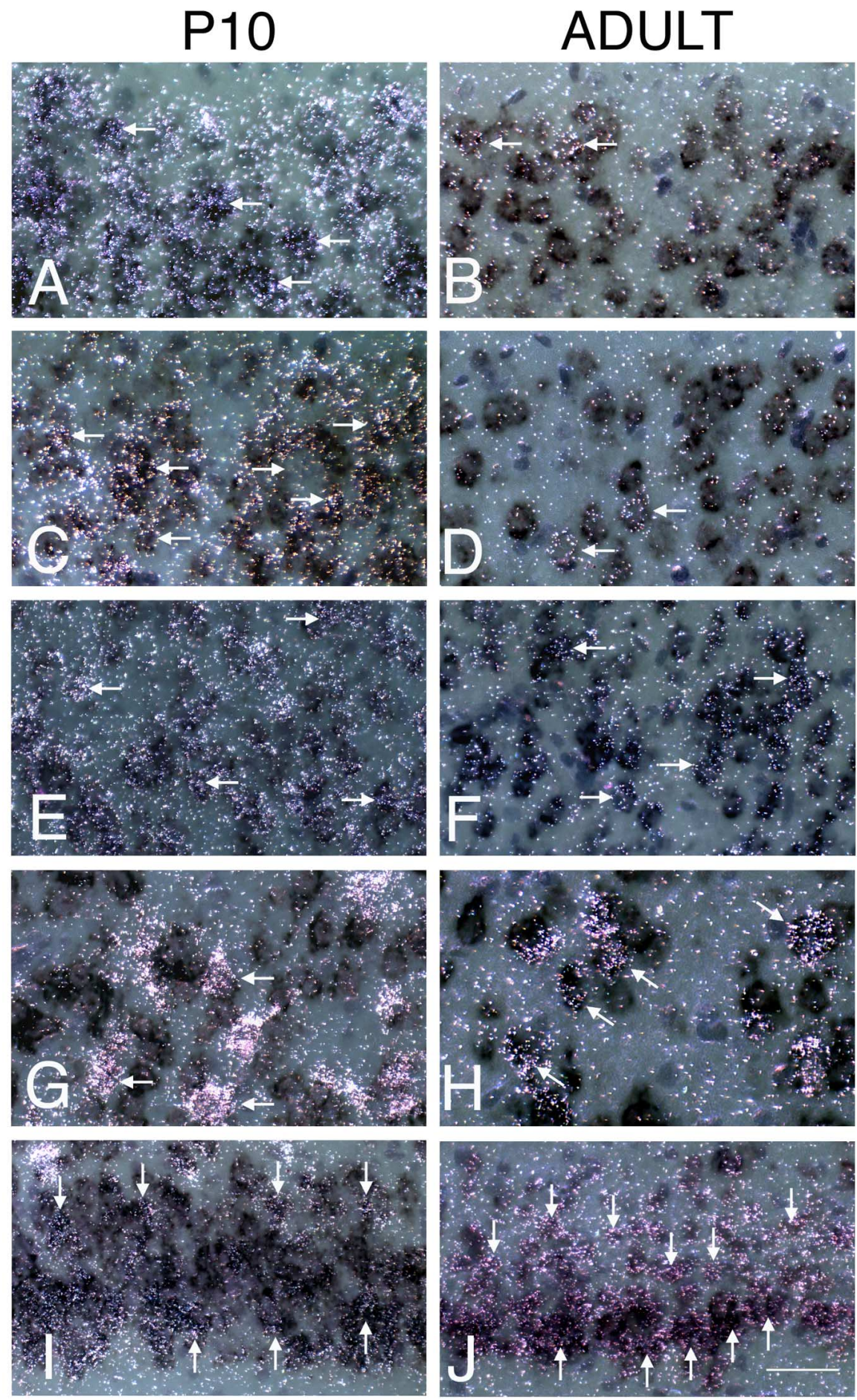

Figure 6. VGLUT1 and VGLUT2 are coexpressed in subsets of neocortical neurons in situ. High-power micrograph of emulsiondipped autoradiograms illustrating the coexpression of VGLUT2 mRNA transcripts (detected with radiolabeled probe) and the VGLUT1 mRNA (detected with a digoxigenin-labeled probe) in P10 (left) and adult (right) cortical regions. $\boldsymbol{A}, \boldsymbol{B}$, Parietal cortex layer II/III. C, D, Auditory cortex layer II/III. Note that most neurons in layer II/III coexpress VGLUT1 and VGLUT2 at P10, whereas labeling is only slightly above background in few adult cells (arrows). $\boldsymbol{E}, \boldsymbol{F}$, Parietal cortex layer IV. G, H, Auditory cortex layer V/VI. Note the high level of VGLUT2 expression and coexpression with VGLUT1 at P10 and subpopulation of neurons expressing moderate levels in adult (arrows). I, J, Posterior cingulate cortex (retrosplenial cortex). Note moderate levels of VGLUT2 expression and coexpression with VGLUT1 at P10 and in adult (arrows). Scale bar, $50 \mu \mathrm{m}$.

\section{Scaling of vesicular glutamate and GABA transporter expression}

The strength of a synapse can be altered presynaptically by at least two mechanisms: (1) by changing the probability that a synaptic vesicle will undergo exocytosis and release its content and (2) by changing the amount of transmitter contained in each synaptic vesicle. The latter can be achieved by scaling the amount of vesicular transporter protein per vesicle, which increases or decreases the vesicular loading capacity and thereby regulates the quantal size of transmitter release (Wilson et al., 2005). Alterations in the cytoplasmic levels of glutamate and GABA available for vesicular sequestration also result in corresponding changes in vesicular storage and release (Engel et al., 2001; Yamashita et al., 2003). The set point of synaptic vesicle glutamate and GABA storage might therefore be controlled by the number of functional transporters and the cytoplasmic transmitter concentration (Wilson et al., 2005) similarly to that described for the vesicular acetylcholine transporter after heterologous gene expression (Varoqui and Erickson, 1996, 1997), supporting a steady-state equilibrium model of vesicle transmitter packet size (Williams, 1997). The rate of vesicular transmitter uptake (Fon et al., 1997; Song et al., 1997) and the size of synaptic vesicles have also been considered to be determinants of quantal size (Bruns et al., 2000; Colliver et al., 2000; Pothos et al., 2000; Sulzer and Pothos, 2000; Karunanithi et al., 2002; Van der Kloot et al., 2002; Gong et al., 2003). VGLUT1 overexpression at excitatory synapses of Drosophila results in an increase in vesicle volume, which is accompanied by an increase in quantal size of glutamate measured postsynaptically (Daniels et al., 2004). VGLUT1/synapsin intensity ratios at excitatory hippocampal pyramidal neuron synapses decrease after endogenous hyperexcitation (via $\mathrm{GABA}_{\mathrm{A}}$ receptor blockade) and lead to a decrease in the exocytotic release of glutamate from single vesicles (Wilson et al., 2005). We show that VGLUT1 and VIAAT mRNA levels and VGLUT1/synaptophysin and VIAAT/synaptophysin intensity ratios at single synapses change in opposite manner in synaptically differentiated neocortical neurons after prolonged activity changes. This indicates that a coordinated set of presynaptic molecular and subcellular modifications occur to adjust vesicular transporter levels on vesicles as determinants of vesicular quantal size.

Global downregulation of VGLUT1 in all neocortical excitatory synapses coupled with upregulation of VGLUT2 at a specific subpopulation of synapses after prolonged BIC treatment would enable some excitatory synapses to remain "strong" and correct the hyperactivity of the circuit (e.g., an excitatory synapse onto an inhibitory neuron). Interestingly, VGLUT2 may play such a role 

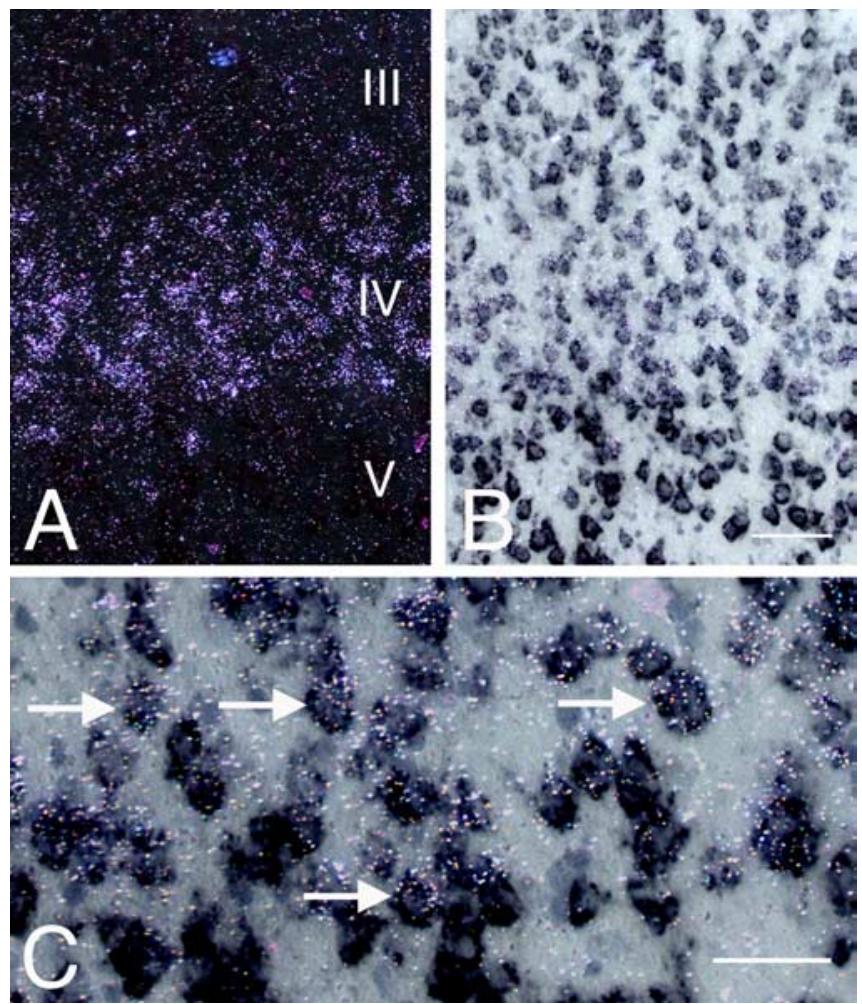

Figure 7. VGLUT1 and VGLUT2 are coexpressed in layer IV neurons in adult neocortex in situ. High- and low-power images of layer IV neurons after double-labeled ISHH for VGLUT2 $\left({ }^{35} \mathrm{~S}\right.$ labeled; left) and VGLUT1 (Dig-labeled; right). $\boldsymbol{A}$, Dark field; $\boldsymbol{B}$, bright field. Note the obvious VGLUT2 labeling $(\boldsymbol{A}, \boldsymbol{B})$ and reduction of VGLUT1 labeling $(\boldsymbol{B})$ in layer IV compared with layer III and V. $C$, Higher-power image showing numerous labeled small oval/rounded neurons copositive for VGLUT1 and VGLUT2 (arrows). Scale bars: $A, B, 100 \mu \mathrm{m} ; C, D, 50 \mu \mathrm{m}$.

in cholinergic motoneurons via a recurrent collateral pathway onto Renshaw inhibitory neurons (Herzog et al., 2004). Recurrent pyramidal neuron excitatory terminals display differential targeting to subclasses of GABA neurons in the cerebral cortex (DeFelipe, 2002; Melchitzky and Lewis, 2003; Maffei et al., 2004), some of which may provide powerful feedback inhibition onto pyramidal neurons (Reyes et al., 1998; Gupta et al., 2000; McBain and Fisahn, 2001; Markram et al., 2004; Turrigiano and Nelson, 2004). It has been shown in an individual neocortical pyramidal neuron that a $48 \mathrm{~h}$ treatment with BIC results in a reduction in quantal amplitude at its cortico-excitatory synapse (feedforward) and an increase in quantal amplitude at its cortico-GABAergic synapse (feedback), which may be attributable, in part, to postsynaptic changes (Rutherford et al., 1997, 1998; Turrigiano et al., 1998). Although we cannot presently determine whether glutamate release is maintained or increased at VGLUT2-expressing synapses after BIC treatment, the increase in the number of VGLUT2 molecules may offset the decrease in the number of VGLUT1 molecules observed in coexpressing synaptic terminals and prevent a decrease in synaptic vesicle filling with glutamate. If VGLUT2 is upregulated in only a subset of individual synapses, VGLUT1/VGLUT2 coexpressing neurons might thereby have the ability to selectively modulate the presynaptic strength of selective synapses. Alternatively, dually encoded excitatory neurons may upregulate or downregulate VGLUT2 and VGLUT1 at all of their synapses, possibly endowing these terminals with vesicles exhibiting different release probabilities. VGLUT1- and VGLUT2-encoded hippocampal synapses may exhibit differences in the probability of glutamate release (Fremeau et al.,

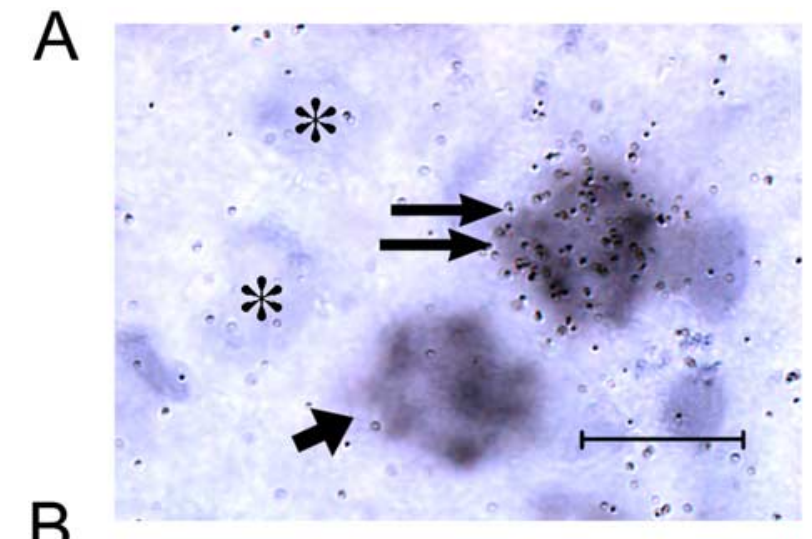

$B$
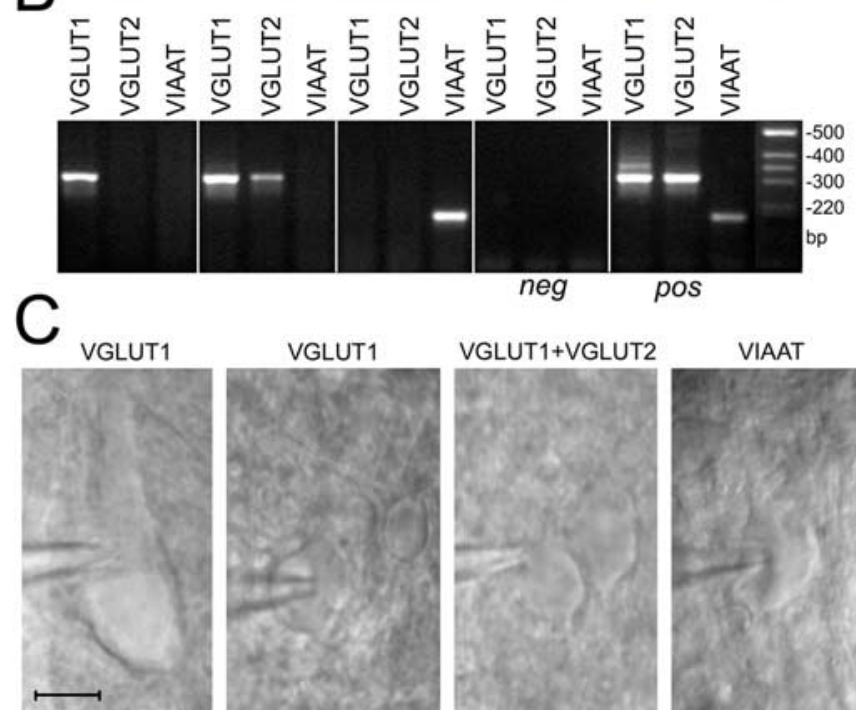

VIAAT

Figure 8. VGLUT1 and VGLUT2 are coexpressed in layer IV neurons in adult neocortex in vivo. $\boldsymbol{A}$, High-resolution images of adult layer IV neurons by double-ISHH reveals specificity of ${ }^{35} \mathrm{~S}$ VGLUT2 and Dig-VGLUT1 probes by double-labeled ISHH. Note the presence of small round/oval neurons labeled by both VGLUT1 and VGLUT2 (double arrow), VGLUT1 only (short arrow), or unlabeled $\left({ }^{*}\right)$. Scale bar, $20 \mu \mathrm{m}$. $\boldsymbol{B}$, Single-cell RT-PCR analysis of pyramidal-shaped neurons and small oval/rounded neurons from the somatosensory cortex barrel region in layer IV reveals the existence of multiple classes of neurons characterized by expression of mRNAs encoding VGLUT1, both VGLUT1 and VGLUT2, and VIAAT. VGLUT1 and VGLUT2 bands detected were of the appropriate size, and their identity was further confirmed by the restriction pattern of Hincll. Positive (pos) and negative (neg) controls: $500 \mathrm{pg}$ of total RNA at DIV21 and internal pipette solution were used as template for reverse transcription, respectively. C, DIC images of representative cell types used for RT-PCR analysis.

2004b; Wojcik et al., 2004), and individual terminals can be differentially potentiated depending on their initial release probability (Dobrunz and Stevens, 1997; Reyes et al., 1998; Berninger et al., 1999). Furthermore, differential trafficking mechanisms of VGLUT1 and VGLUT2 during synaptic vesicle recycling at synapses is likely given the divergence in primary amino acid sequences in cytoplasmic regions of these proteins (Fremeau et al., 2004a).

\section{Coexpression of VGLUT1 and VGLUT2 in discrete populations of neocortical neurons}

The activity-dependent changes in VGLUT2 expression reported here likely occurs in a distinct set of neocortical neurons that we have identified in primary neuronal cultures in situ and in vivo that coexpress VGLUT1 and VGLUT2. By double-labeled ISHH, we show that these neurons are predominantly found in many small neurons in layer IV but also in subsets of neurons in pyra- 
midal neuronal layers II/III and V/VI in the parietal, auditory (temporal), and posterior cingulate cortex. In mature neurons, VGLUT1 is present in most of the VGLUT2-expressing neurons observed. Indeed, single-cell RT-PCR of cytoplasm from individual layer IV excitatory neuronal cell bodies of adult rat cortex slices indicates the presence of VGLUT1-encoded pyramidalshaped neurons and significant subpopulations of VGLUT1/ VGLUT2 coexpressing and VGLUT1-only oval/round-shaped neurons, which may represent spiny layer IV excitatory neurons. These latter cells, which include spiny stellate and star pyramidal neurons (Cowan and Stricker, 2004; Staiger et al., 2004), receive predominantly VGLUT2-encoded thalamic excitatory input (Hisano et al., 2000; Fujiyama et al., 2001) and distribute this subcortical input to target cells in other cortical layers, in particular to those in layer II/III, but also to layer V/VI neurons (Feldmeyer et al., 1999), in which we also show the presence of VGLUT1/VGLUT2 coexpressing neurons. Interestingly, the star pyramidal neurons of layer IV in visual cortex have been implicated recently in driving activity-dependent changes in E/I balance that results from monocular deprivation during development (Maffei et al., 2004). Coexpression of VGLUT1 and VGLUT2 in individual sets of neocortical neurons would enable independent regulation of these genes and functional diversity in vesicular glutamate storage at excitatory synapses.

\section{Presynaptic E/I balance in neocortical circuits}

In mature neocortical neurons, a coordinated homeostatic scaling of the level of expression of VGLUT1 and VIAAT mRNA and synaptic protein may serve to regulate transporter levels on synaptic vesicles to adjust quantal size of transmitter available for release. Homeostatic plasticity at both excitatory and inhibitory neocortical synapses also include alterations in the postsynaptic response to glutamate and GABA by scaling the number of glutamate and GABA receptors (Rutherford et al., 1997, 1998; Turrigiano et al., 1998; Kilman et al., 2002; Ju et al., 2004) and level of synaptic depolarization by alterations in ionic conductances (Leslie et al., 2001; van Welie et al., 2004). Postsynaptic receptor changes appear to predominate in young neocortical cultures (DIV7-DIV10) (Wierenga et al., 2005) before the massive endogenous upregulation of VGLUT1 and VIAAT that occurs during synaptic differentiation. Our results are consistent with the notion that, in mature neocortical neurons, homeostatic plasticity includes both presynaptic and postsynaptic alterations that act synergistically to modify the strength of excitatory and inhibitory synapses. Thus, BIC treatment produces a coordinated set of changes in synaptic strength that would result in reduced feedback excitation (VGLUT1 down) and increased feedback inhibition (VIAAT up) onto pyramidal neurons (Turrigiano and Nelson, 2004). Conversely, blocking activity for $2 \mathrm{~d}$ with TTX increases the gain of excitatory feedback (VGLUT1 up) and decreases inhibitory feedback (VIAAT down). Because VGLUT1 and VIAAT are the transporters expressed at the majority of excitatory and inhibitory synapses on pyramidal neuron dendrites in neocortical circuits, bidirectional and opposite changes in the expression of these vesicular proteins represents an intrinsic way for these neurons to adjust their vesicular transmitter stores that are available for release to restore E/I balance. Opposing activitydependent regulation of VGLUT1 and VGLUT2 in neurons that express both transporters may provide a dual mechanism for controlling the filling of vesicles in discrete excitatory terminals. Intracortical VGLUT1/VGLUT2 cooperated neurons are endowed with a unique versatility to fine tune the synaptic expression of these transporters and hence quantal size at individual synapses. Dysfunctions in this capability may underlie neurological and psychiatric diseases involving the neocortex in particular epilepsia, schizophrenia, and depression. Future studies may lead to an additional understanding of how endogenous regulation of VGLUTs and VIAAT may affect the development of cortical connectivity and the responsiveness of individual neocortical neurons and synapses to activity.

\section{References}

Atwood HL, Karunanithi S (2002) Diversification of synaptic strength: presynaptic elements. Nat Rev Neurosci 3:497-516.

Axmacher N, Stemmler M, Engel D, Draguhn A, Ritz R (2004) Transmitter metabolism as a mechanism of synaptic plasticity: a modeling study. J Neurophysiol 91:25-39.

Bellocchio EE, Hu H, Pohorille A, Chan J, Pickel VM, Edwards RH (1998) The localization of the brain-specific inorganic phosphate transporter suggests a specific presynaptic role in glutamatergic transmission. J Neurosci 18:8648-8659.

Bellocchio EE, Reimer RJ, Fremeau RT, Edwards RH (2000) Uptake of glutamate into synaptic vesicles by an inorganic phosphate transporter. Science 289:957-960.

Berninger B, Schinder AF, Poo MM (1999) Synaptic reliability correlates with reduced susceptibility to synaptic potentiation by brain-derived neurotrophic factor. Learn Mem 6:232-242.

Boulland JL, Qureshi T, Seal RP, Rafiki A, Gundersen V, Bergersen LH, Fremeau RT, Edwards RH, Storm-Mathisen J, Chaudhry FA (2004) Expression of the vesicular glutamate transporters during development indicates the widespread corelease of multiple neurotransmitters. J Comp Neurol 480:264-280.

Brecht M, Sakmann B (2002) Dynamic representation of whisker deflection by synaptic potentials in spiny stellate and pyramidal cells in the barrels and septa of layer 4 rat somatosensory cortex. J Physiol (Lond) 543:49-70.

Brewer GJ, Torricelli JB, Evege EK, Price PJ (1993) Optimized survival of hippocampal neurons in B7-supplemented Neurobasal, a new serum-free medium combination. J Neurosci Res 35:567-576.

Bruns D, Riedel D, Klingauf J, Jahn R (2000) Quantal release of serotonin. Neuron 28:205-220.

Burrone J, O’Byrne M, Murthy VN (2002) Multiple forms of synaptic plasticity triggered by selective suppression of activity in individual neurons. Nature 420:414-418.

Cauli B, Audinat E, Lambolez B, Angulo MC, Ropert N, Tsuzuki K, Hestrin S, Rossier J (1997) Molecular and physiological diversity of cortical nonpyramidal cells. J Neurosci 17:3894-3906.

Chen C, Magee JC, Bazan NG (2002) Cyclooxygenase-2 regulates prostaglandin $\mathrm{E}_{2}$ signaling in hippocampal long-term synaptic plasticity. J Neurophysiol 87:2851-2857.

Cline H (2005) Synaptogenesis: a balancing act between excitation and inhibition. Curr Biol 15:R203-R205.

Colliver TL, Pyott SJ, Achalabun M, Ewing AG (2000) VMAT-mediated changes in quantal size and vesicular volume. J Neurosci 20:5276-5282.

Cowan AI, Stricker C (2004) Functional connectivity in layer IV local excitatory circuits of rat somatosensory cortex. J Neurophysiol 92:2137-2150.

Dal Bo G, St-Gelais F, Danik M, Williams S, Cotton M, Trudeau LE (2004) Dopamine neurons in culture express VGLUT2 explaining their ability to release glutamate at synapses in addition to dopamine. J Neurochem 88:1398-1405.

Daniels RW, Collins CA, Gelfand MV, Dant J, Brooks ES, Krantz DE, DiAntonio A (2004) Increased expression of the Drosophila vesicular glutamate transporter leads to excess glutamate release and a compensatory decrease in quantal content. J Neurosci 24:10466-10474.

Davis GW, Bezprozvanny I (2001) Maintaining the stability of neural function: a homeostatic hypothesis. Annu Rev Physiol 63:847-869.

DeFelipe J (2002) Cortical interneurons: from Cajal to 2001. Prog Brain Res 136:215-238.

Dobrunz LE, Stevens CF (1997) Heterogeneity of release probability, facilitation, and depletion at central synapses. Neuron 18:995-1008.

Engel D, Pahner I, Schulze K, Frahm C, Jarry H, Ahnert-Hilger G, Draguhn A (2001) Plasticity of rat central inhibitory synapses through GABA metabolism. J Physiol (Lond) 535:473-482.

Feldmeyer D, Egger V, Lübke J, Sakmann B (1999) Reliable synaptic connections between pairs of excitatory layer 4 neurons within a single barrel of developing rat somatosensory cortex. J Physiol (Lond) 521:169-190. 
Fon EA, Pothos EN, Sun BC, Killeen N, Sulzer D, Edwards RH (1997) Vesicular transport regulates monoamine storage and release but is not essential for amphetamine action. Neuron 19:1271-1283.

Fremeau RT, Troyer MD, Pahner I, Nygaard GO, Tran CH, Reimer RJ, Bellocchio EE, Fortin D, Storm-Mathisen J, Edwards RH (2001) The expression of vesicular glutamate transporters defines two classes of excitatory synapse. Neuron 31:247-260.

Fremeau RT, Voglmaier S, Seal RP, Edwards RH (2004a) VGLUTs define subsets of excitatory neurons and suggest novel roles for glutamate. Trends Neurosci 27:98-103.

Fremeau RT, Kam K, Qureshi R, Johnson J, Copenhagen DR, StormMathisen J, Chaudhry FA, Nicoll RA, Edwards RH (2004b) Vesicular glutamate transporters 1 and 2 target to functionally distinct synaptic release sites. Science 304:1815-1819.

Frerking M, Borges S, Wilson M (1995) Variation in GABA mini amplitude is the consequence of variation in transmitter concentration. Neuron 15:885-895.

Fujiyama F, Furuta R, Kaneko T (2001) Immunocytochemical localization of candidates for vesicular glutamate transporters in the rat cerebral cortex. J Comp Neurol 435:379-387.

Gong LW, Hafez I, Alvarez de Toledo G, Lindau M (2003) Secretory vesicles membrane area is regulated in tandem with quantal size in chromaffin cells. J Neurosci 23:7917-7921.

Gupta A, Wang Y, Markram H (2000) Organizing principles for a diversity of GABAergic interneurons and synapses in the neocortex. Science 287:273-278.

Hajos N, Nusser Z, Rancz EA, Freund TF, Mody I (2000) Cell type-and synapse-specific variability in synaptic $\mathrm{GABA}_{\mathrm{A}}$ receptor occupancy. Eur J Neurosci 12:810-818.

Heaulme M, Chambon JP, Leyris R, Molimard JC, Wemuth CG, Biziere K (1986) Biochemical characterization of the interaction of three pyridazinyl-GABA derivatives with the GABAA receptor site. Brain Res 384:224-231.

Herzog E, Bellenchi GC, Gras C, Bernard V, Ravassard P, Bedet C, Gasnier B, Giros B, El Mestikawy S (2001) The existence of a second vesicular glutamate transporter specifies subpopulations of glutamatergic neurons. J Neurosci 21:RC181(1-6).

Herzog E, Landry M, Buhler E, Bouali-Benazzouz R, Legay C, Henderson CE, Nagy F, Dreyfus P, Giros B, El Mestikawy S (2004) Expression of vesicular glutamate transporters, VGLUT1 and VGLUT2, in cholinergic spinal motoneurons. Eur J Neurosci 20:1752-1760.

Hisano S, Hoshi K, Ikeda Y, Maruyama D, Kanemoto M, Ichijo H, Kojima I, Takeda J, Norami H (2000) Regional expression of a gene encoding a neuron-specific $\mathrm{Na}^{+}$-dependent inorganic phosphate cotransporter (DNPI) in the rat forebrain. Mol Brain Res 83:34-43.

Ishikawa T, Sahara Y, Takahashi T (2002) A single packet of transmitter does not saturate postsynaptic glutamate receptors. Neuron 34:613-621.

Ju W, Morishita W, Tsui J, Gaietta G, Deerinck TJ, Adams SR, Garner CC, Tsien RY, Ellisman MH, Malenka RC (2004) Activity-dependent regulation of dendritic synthesis and trafficking of AMPA receptors. Nat Neurosci 7:244-253.

Karunanithi S, Marin L, Wong K, Atwood HL (2002) Quantal size and variation determined by vesicle size in normal and mutant Drosophila glutamatergic synapses. J Neurosci 22:10267-10276.

Kilman V, van Rossum MC, Turrigiano GG (2002) Activity deprivation reduces miniature IPSC amplitude by decreasing the number of postsynaptic $\mathrm{GABA}_{\mathrm{A}}$ receptors clustered at neocortical synapses. J Neurosci 22:1328-1337.

Leslie KR, Nelson SB, Turrigiano GG (2001) Postsynaptic depolarization scales quantal amplitude in cortical pyramidal neurons. J Neurosci 21:RC170(1-6).

Liu G (2003) Presynaptic control of quantal size: kinetic mechanisms and implications for synaptic transmission and plasticity. Curr Opin Neurobiol 13:324-331.

Liu G (2004) Local structural balance and functional interaction of excitatory and inhibitory synapses in hippocampal dendrites. Nat Neurosci 7:373-379.

Liu G, Choi S, Tsien RW (1999) Variability of neurotransmitter concentration and nonsaturation of postsynaptic AMPA receptors at synapses in hippocampal cultures and slices. Neuron 22:395-409.

Lübke J, Egger V, Sakmann B, Feldmeyer D (2000) Columnar organization of dendrites and axons of single and synaptically coupled excitatory spiny neurons in layer 4 of the rat barrel cortex. J Neurosci 20:5300-5311.

Maffei A, Nelson SB, Turrigiano GG (2004) Selective reconfiguration of layer 4 visual cortical circuitry by visual deprivation. Nat Neurosci 7:1353-1359.

Markram H, Toledo-Rodriguez M, Qang Y, Gupta A, Silberberg G, Wu C (2004) Interneurons of the neocortical inhibitory system. Nat Rev Neurosci 5:793-807.

McAllister AK, Stevens CF (2000) Nonsaturation of AMPA and NMDA receptors at hippocampal synapses. Proc Natl Acad Sci USA 97:6173-6178.

McBain CJ, Fisahn A (2001) Interneurons unbound. Nat Rev Neurosci 2:11-23.

McIntire SL, Reimer RJ, Schuske K, Edwards RH, Jorgensen EM (1997) Identification and characterization of the vesicular GABA transporter. Nature 389:870-876.

Melchitzky DS, Lewis DA (2003) Pyramidal neuron local axon terminals in monkey prefrontal cortex: differential targeting of subclasses of GABA neurons. Cereb Cortex 13:452-460.

Minelli A, Alonso-Nanclares L, Edwards RH, DeFelipe J, Conti F (2003a) Postnatal development of the vesicular GABA transporter in rat cerebral cortex. Neuroscience 117:337-346.

Minelli A, Edwards RH, Manzoni T, Conti F (2003b) Postnatal development of the glutamate vesicular transporter VGLUT1 in rat cerebral cortex. Brain Res Dev 140:309-314.

Miyazaki T, Fukaya M, Shimizu H, Watanabe M (2003) Subtype switching of vesicular glutamate transporters at parallel fibre-Purkinje cell synapses in developing mouse cerebellum. Eur J Neurosci 17:2563-2572.

Murthy VN, Schikorski T, Stevens CF, Zhu Y (2001) Inactivity produces increases in neurotransmitter release and synapse size. Neuron 32:673-682.

Ni B, Rosteck PR, Nadi NS, Paul SM (1994) Cloning and expression of a cDNA encoding a brain-specific $\mathrm{Na}^{+}$-dependent inorganic phosphate cotransporter. Proc Natl Acad Sci USA 91:5607-5611.

Ni B, Wu X, Yan GM, Wang J, Paul SM (1995) Regional expression and cellular localization of the $\mathrm{Na}^{+}$-dependent inorganic phosphate cotransporter of rat brain. J Neurosci 15:5789-5799.

Perez-Otano I, Ehlers MD (2005) Homeostatic plasticity and NMDA receptor trafficking. Trends Neurosci 28:229-238.

Pothos EN, Larsen KE, Krantz DE, Liu Y, Haycock JW, Setlik W, Gershon MD, Edwards RH, Sulzer D (2000) Synaptic vesicle transporter expression regulates vesicle phenotype and quantal size. J Neurosci 20:7297-7306.

Reyes A, Lujan R, Rozov A, Burnashev N, Somogyi P, Sakmann B (1998) Target-cell-specific facilitation and depression in neocortical circuits. Nat Neurosci 1:279-285.

Rutherford LC, DeWan A, Lauer HM, Turrigiano GG (1997) Brain-derived neurotrophic factor mediates the activity-dependent regulation of inhibition in neocortical cultures. J Neurosci 17:4527-4535.

Rutherford LC, Nelson SB, Turrigianno GG (1998) BDNF has opposite effects on the quantal amplitude of pyramidal neuron and interneuron excitatory synapses. Neuron 21:521-530.

Sagne C, El Mestikawy S, Isambert MF, Hamon M, Henry JP, Giros B, Gasnier B (1997) Cloning of a functional vesicular GABA and glycine transporter by screening of genome databases. FEBS Lett 417:177-183.

Schäfer MKH, Herman JP, Watson SJ (1993) The imaging of drug action (London ED, ed), pp 337-378. Boca Raton, FL: CRC.

Schäfer MK-H, Varoqui H, Defamie N, Weihe E, Erickson JD (2002) Molecular cloning and functional identification of mouse vesicular glutamate transporter 3 and its expression in subsets of novel excitatory neurons. J Biol Chem 277:50734-50748.

Song H, Ming G, Fon E, Bellocchio E, Edwards RH, Poo M (1997) Expression of a putative vesicular acetylcholine transporter facilitates quantal transmitter packaging. Neuron 18:815-826.

Staiger JF, Flagmeyer I, Schubert D, Zilles K, Kotter R, Luhmann HJ (2004) Functional diversity of layer IV spiny neurons in rat somatosensory cortex: quantitative morphology of electrophysiologically characterized and biocytin labeled cells. Cereb Cortex 14:690-701.

Sulzer D, Pothos EN (2000) Regulation of quantal size by presynaptic mechanisms. Rev Neurosci 11:159-212.

Takamori S, Rhee JS, Rosenmund C, Jahn R (2000) Identification of a vesicular glutamate transporter that defines a glutamatergic phenotype in neurons. Nature 407:189-194. 
Takamori S, Rhee JS, Rosenmund C, Jahn R (2001) Identification of differentiation-associated brain-specific phosphate transporter as a second vesicular glutamate transporter (VGLUT2). J Neurosci 21: RC182(1-6).

Turrigiano GG, Nelson SB (2004) Homeostatic plasticity in the developing nervous system. Nat Rev Neurosci 5:97-107.

Turrigiano GG, Leslie KR, Desai NS, Rutherford LC, Nelson SB (1998) Activity-dependent scaling of quantal amplitude in neocortical neurons. Nature 391:892-896.

Van der Kloot W, Molgo J, Cameron R, Colasante C (2002) Vesicle size and transmitter release at the frog neuromuscular junction when quantal acetylcholine content is increased or decreased. J Physiol (Lond) 541:385-393.

van Welie I, van Hooft JA, Wadman WJ (2004) Homeostatic scaling of neuronal excitability by synaptic modulation of somatic hyperpolarizationactivated Ih channels. Proc Natl Acad Sci USA 101:5123-5128.

Varoqui H, Erickson JD (1996) Active transport of acetylcholine by the human vesicular acetylcholine transporter. J Biol Chem 271:27229-27232.

Varoqui H, Erickson JD (1997) Vesicular neurotransmitter transporters.
Potential sites for the regulation of synaptic function. Mol Neurobiol 15:165-191.

Varoqui H, Schäfer MK-H, Zhu H, Weihe E, Erickson JD (2002) Identification of the differentiation-associated $\mathrm{Na}^{+} /$Pi transporter as a novel vesicular glutamate transporter expressed in a distinct set of glutamatergic synapses. J Neurosci 22:142-155.

Wierenga CJ, Ibata K, Turrigiano GG (2005) Postsynaptic expression of homeostatic plasticity at neocortical synapses. J Neurosci 25:2895-2905.

Williams J (1997) How does a vesicle know it is full? Neuron 18:683-686.

Wilson NR, Kang J, Hueske EV, Leung T, Varoqui H, Murnick JG, Erickson JD, Liu G (2005) Presynaptic regulation of quantal size by VGLUT1. J Neurosci 25:6221-6234.

Wojcik SM, Rhee JS, Herzog E, Sigler, A, Jahn R, Takamori S, Brose N, Rosenmund C (2004) An essential role for vesicular glutamate transporter 1 (VGLUT1) in postnatal development and control of quantal size. Proc Natl Acad Sci USA 101:7158-7163.

Yamashita T, Ishikawa T, Takahashi T (2003) Developmental increase in vesicular glutamate content does not cause saturation of AMPA receptors at the calyx of held synapse. J Neurosci 23:3633-3638. 